\title{
Enhanced Cleavage of Type II Collagen by Collagenases in Osteoarthritic Articular Cartilage
}

\author{
R. Clark Billinghurst, ${ }^{\star}$ Leif Dahlberg, ${ }^{\star}$ Mirela lonescu, ${ }^{\star}$ Agnes Reiner, ${ }^{*}$ Robert Bourne, ${ }^{\ddagger}$ Cecil Rorabeck, ${ }^{\ddagger}$ Peter Mitchell, ${ }^{\S}$ \\ John Hambor, $\$$ Oliver Diekmann," Harald Tschesche, "Jeffrey Chen," Hal Van Wart," and A. Robin Poole* \\ *Joint Diseases Laboratory, Shriners Hospital for Crippled Children, Division of Surgical Research, Department of Surgery, McGill \\ University, Montreal, Quebec, H3G 1A6, Canada; ${ }^{\ddagger}$ Division of Orthopaedic Surgery, University Hospital, University of Western Ontario, \\ London, Ontario, N6A 5A5, Canada; ${ }^{\S}$ Central Research Division, Pfizer Incorporated, Groton, Connecticut 06340; $"{ }^{D e p a r t m e n t ~ o f ~}$ \\ Biochemistry, University of Bielefeld, D-33615, Bielefeld, Germany; and ${ }^{\mathbb{T}}$ Roche Bioscience, Palo Alto, California $94304-9819$
}

\begin{abstract}
We demonstrate the direct involvement of increased collagenase activity in the cleavage of type II collagen in osteoarthritic human femoral condylar cartilage by developing and using antibodies reactive to carboxy-terminal (COL2-3/ $4 \mathrm{C}_{\text {short }}$ ) and amino-terminal (COL2-1/4N1) neoepitopes generated by cleavage of native human type II collagen by collagenase matrix metalloproteinase (MMP)-1 (collagenase-1), MMP-8 (collagenase-2), and MMP-13 (collagenase-3). A secondary cleavage followed the initial cleavage produced by these recombinant collagenases. This generated neoepitope COL2-1/4N2. There was significantly more COL2-3/ $4 \mathrm{C}_{\text {short }}$ neoepitope in osteoarthritis (OA) compared to adult nonarthritic cartilages as determined by immunoassay of cartilage extracts. A synthetic preferential inhibitor of MMP-13 significantly reduced the unstimulated release in culture of neoepitope COL2-3/4C $\mathrm{C}_{\text {short }}$ from human osteoarthritic cartilage explants. These data suggest that collagenase(s) produced by chondrocytes is (are) involved in the cleavage and denaturation of type II collagen in articular cartilage, that this is increased in OA, and that MMP-13 may play a significant role in this process. (J. Clin. Invest. 1997. 99:15341545.) Key words: matrix metalloproteinases - arthritis • chondrocytes $\bullet$ antibodies
\end{abstract}

\section{Introduction}

Type II collagen is composed of a triple helix of three identical $\alpha$ chains. These molecules associate to form a fibril that is stabilized by intermolecular crosslinks (1). The fibrils provide the tensile strength and maintain the integrity of mammalian artic-

A preliminary report of this study was presented at the Gordon Research Conference on metalloproteinases, June 1995.

Address correspondence to R. Clark Billinghurst, Joint Diseases Laboratory, Shriners Hospital for Crippled Children, McGill University, Division of Surgical Research, Department of Surgery, Montreal, Québec, H3G 1A6, Canada. Phone: 514-849-6208; FAX: 514-842-5581; E-mail: cbillinghurst@shriners.mcgill.ca L. Dahlberg's current address is Department of Orthopedics, Malmo General Hospital, S-21401 Malmo, Sweden.

Received for publication 7 July 1996 and accepted in revised form 17 January 1997.

J. Clin. Invest.

(C) The American Society for Clinical Investigation, Inc. 0021-9738/97/04/1534/12 \$2.00

Volume 99, Number 7, April 1997, 1534-1545 ular cartilage by forming a network that resists the swelling pressure resulting from the hydration of the polyanionic proteoglycan aggregates in the extracellular matrix $(2,3)$. Damage to this fibrillar meshwork, made up of primarily type II collagen $(\sim 90-95 \%)$, may be a critical event in the pathology of many arthritides, due in part to the very slow rate of collagen turnover within the cartilage (4). In early degeneration in articular cartilage, which may lead to osteoarthritis $(\mathrm{OA})^{1}$, there is a loss of the tensile properties, indicative of damage to the fibrillar network (2). Recent studies in this laboratory have provided evidence for increased denaturation of the triple helix of type II collagen in human articular cartilage in OA (5-7).

The extracellular degradation of fibrillar types I, II, and III collagens can occur both in nonhelical sites (8) and through a triple helical cleavage. Only the latter results in denaturation of the triple helix at physiological temperatures. This is achieved by collagenases which belong to the family of zinc-dependent endopeptidases called matrix metalloproteinases (MMPs). Collagenase-1 or MMP-1 (interstitial collagenase), collagenase- 2 or MMP-8 (neutrophil collagenase), and the recently cloned and characterized collagenase- 3 or MMP-13 $(9,10)$ are the only mammalian enzymes known to be able to initiate the intrahelical cleavage of triple helical collagen at neutral $\mathrm{pH}$. MMP-3 (stromelysin-1) can cleave type II fibrillar collagen, but only in the nonhelical amino-telopeptide domain (11). These collagenases are thought to define the rate-limiting step in normal tissue remodeling events such as bone resorption and growth, embryonic development, uterine involution, wound healing, and in degradative processes such as arthritis, tumor invasion and metastasis, and periodontitis.

Until now, there has been no direct evidence for their involvement in intrahelical cleavage, except for the inability of murine collagenase to cleave type I collagen in vivo when the intrahelical site is mutated (8). These three collagenases cleave the fibrillar collagens type I, II, and III at a single site (Gly (775 $-\mathrm{Leu} /$ Ile $_{776}$ ) within each $\alpha$ chain of the triple helical collagen molecule, approximately three quarters of the distance from the amino-

1. Abbreviations used in paper: APMA, aminophenyl mercuric acetate; COL2-3/4C, type II collagen three-quarter fragment primary collagenase cleavage site carboxy-terminal neoepitope; COL2-1/4N2, type II collagen one-quarter fragment secondary collagenase cleavage site amino-terminal neoepitope; COL2-3/4m, type II collagen three-quarter fragment intrachain epitope; $\mathrm{F}\left(\mathrm{ab}^{\prime}\right)_{2}$, pepsin-generated divalent antibody fragment; MMP, matrix metalloproteinase; OA, osteoarthritis; OVA, ovalbumin; TC $^{\mathrm{A}}$, three-quarter collagen fragment; $\mathrm{TC}^{\mathrm{B}}$, one-quarter collagen fragment; TIMP, tissue inhibitor of metalloproteinases. 
terminal end of each chain, resulting in the generation of threequarter $\left(\mathrm{TC}^{\mathrm{A}}\right)$ and one-quarter $\left(\mathrm{TC}^{\mathrm{B}}\right)$ length collagen fragments (12-14). The cleaved collagen fragments spontaneously denature into nonhelical gelatin derivatives at physiological temperatures, thereby becoming susceptible to further degradation by these collagenases (15) and/or by other proteinases, such as MMP-3, and the gelatinases MMP-2 and MMP-9.

Collagenases have been detected in the synovial fluid of patients with traumatic arthritis, RA, and OA (16-19). In the synovial joint, there are three distinct tissue sources of the collagenases that may be involved in the degradation of articular cartilage. Cells in OA and RA synovium express collagenases (20-23). The expression of MMP-13 in the synovial membrane was identified in RA and OA tissues in one study (24), but in other reports MMP-13 was not found in isolated synoviocytes from OA and RA patients, nor could it be induced in these cells by IL-1 $(25,26)$. Fibroblasts at the cartilage-pannus interface also secrete a collagenase that can degrade cartilage (27). Chondrocytes express and secrete MMP-1 $(22,25,26,28)$ and MMP-13 $(14,25,26)$ in both normal and OA articular cartilages. This is upregulated by IL-1 (14). Moreover, two recent studies describe the expression of MMP-8 (neutrophil collagenase) by human articular chondrocytes from normal donors, and its upregulation by IL-1 $(29,30)$.

Collagenases have been routinely assayed in vitro $(31,32)$ and in vivo $(33,34)$ using radiolabeled collagen fibrils or fluorogenic peptides (35). These methods do not allow for the differentiation of the collagenases involved in the cleavage of these substrates. ELISAs have been developed using specific anticollagenase antibodies allowing the detection of collagenase and tissue inhibitor of metalloproteinase (TIMP)-collagenase complexes (36-38). However, the presence of enzyme in body fluids and tissues does not necessarily imply activity, as the collagenases are secreted as zymogens, they require activation, and their catalytic potential is determined by the presence of inhibitors such as tissue inhibitor of metalloproteinase and alpha $_{2}$ macroglobulin.

Using polyclonal and monoclonal antibodies that react specifically to denatured type II collagen $\alpha$ chains, such as can result from intrahelical cleavage by collagenases, we have shown that increased denaturation of this molecule can be detected in OA articular cartilages (5-7). This implicates collagenases in the denaturation of type II collagen. However, to definitively demonstrate a role for these proteinases in the cleavage of this molecule, a means of specifically identifying the collagenase cleavage site(s) in situ is required. This would be possible if we could prepare and use antibodies that react with the carboxy(COOH-) and amino- $\left(\mathrm{NH}_{2}^{-}\right)$terminal neoepitopes created by cleavage of collagen by collagenases and which do not react with the intact molecule or $\alpha$ chains thereof. Antibodies of this kind prepared to cleavage site neoepitopes have already proven valuable in defining MMP activity in aggrecan degradation (39-45).

In this study, we have developed, for the first time, antibodies to the neoepitopes that represent the $\mathrm{COOH}$ - and $\mathrm{NH}_{2}$ termini of $\mathrm{TC}^{\mathrm{A}}$ and $\mathrm{TC}^{\mathrm{B}}$, respectively, of human type II collagen $\alpha$ chains, produced by cleavage of the triple helical collagen molecule by any one of the three collagenases: MMP-1, MMP-8, and MMP-13. Here we describe how these antineoepitope antisera were used to provide direct evidence for the involvement of collagenases in the cleavage of type II collagen in osteoarthritic human articular cartilages. Moreover, we show that there is a direct association between this cleavage and the denaturation of type II collagen. Finally, through the use of a synthetic preferential inhibitor of MMP-13, we provide evidence that indicates that the in vitro release of collagenasespecific type II collagen cleavage site neoepitopes from OA articular cartilage is usually mediated by MMP-13.

\section{Methods}

Tissue. Human adult and fetal articular cartilages, and human fetal skin were collected at autopsy (within $15 \mathrm{~h}$ postmortem) and from therapeutic abortions. Full-depth human osteoarthritic articular femoral condylar cartilage was obtained at arthroplasty from the knee joints of 26 patients with OA, as diagnosed using the criteria of the American College of Rheumatology for OA (46). Osteophytic cartilages were never examined. Macroscopically normal full-depth nonarthritic articular cartilages were obtained within $15 \mathrm{~h}$ of postmortem from the femoral condylar regions of 19 individuals from sites where there were no observable joint abnormalities. None of these persons had recent chemotherapy.

Collagen purification. Human type II collagen was prepared by pepsin digestion and differential salt precipitation, using the method of Miller (47). Human types I and III collagen were prepared by pepsin digestion and differential denaturation and renaturation (48). Bovine type X collagen was provided by Dr. A. Marriott (Joint Diseases Laboratory, Montreal, Canada). Cyanogen bromide ( $\mathrm{CNBr}$ ) peptides of human type II were prepared as described by Dodge and Poole (5).

Preparation of recombinant human proMMP-1, proMMP-8, and proMMP-13. Recombinant human proMMP-1 and proMMP-13 were purified from the culture medium of $\mathrm{Sf} 9$ cells that were infected with recombinant baculovirus, as described recently (14). Briefly, proMMP-1 was affinity purified using a monoclonal antibody column and proMMP-13 was purified using heparin-agarose and SP-Sepharose Fast Flow columns. Both the enzymes were $>95 \%$ pure as determined by Coomassie blue staining of SDS-PAGE gels. Recombinant human proMMP-8 was expressed in Escherichia coli as inclusion body protein, refolded, and purified as previously described (49).

Identification and synthesis of type II collagen collagenase cleavage site neoepitopes. For both the neoepitope peptides COL2-3/ $4 \mathrm{C}_{\text {short }}$ (Gly-Pro-Hyp-Gly-Pro-Gln-Gly), which corresponds to the $\mathrm{COOH}$ terminus of $\mathrm{TC}^{\mathrm{A}}$, and COL2-1/4N1 (Leu-Ala-Gly-Gln-ArgGly), corresponding to the $\mathrm{NH}_{2}$ terminus of $\mathrm{TC}^{\mathrm{B}}$ of the primary cleavage of native triple helical human type II collagen produced by collagenase-1 (MMP-1), amino acid sequences for their synthesis were based on published amino acid sequences (50) of fibroblast collagenase (MMP-1) cleaved human type II collagen alpha $1(\alpha 1)$ chains (Fig. 1), with the following exception. The assignment of the third residue of the COL2-3/4C $\mathrm{C}_{\text {short }}$ peptide (hereafter referred to only as COL2-3/4C), as a hydroxylated proline (Hyp) was based on the assumption that proline residues in the $\mathrm{Y}$ position of the repeating Gly-X-Y triplets that make up the helical portions of collagen molecules are potential hydroxylation sites within the collagen $\alpha$ chains. Moreover, we have shown that antisera generated to peptides containing a nonhydroxylated proline at this position react poorly to the cleaved $\mathrm{TC}^{\mathrm{A}}$ of type II collagen and in turn, these peptides lacking hydroxylated proline, are recognized less effectively by antiserum generated from the COL2-3/ $4 \mathrm{C}$ peptide containing the hydroxylated proline residue (unpublished observations). The sequence for neoepitope peptide COL2-1/4N2 (Gln-Arg-Gly-Ile-Val-Gly), representing a secondary (N2) collagenase cleavage site at the $\mathrm{NH}_{2}$ terminus of the human $\alpha 1$ (II) $\mathrm{TC}^{\mathrm{B}}$, was determined using the methodology described recently (12).

These peptides (COL2-3/4C, COL2-1/4N1, and COL2-1/4N2) and those peptides used for epitope analyses and antisera characterization, as described below, were synthesized at a $0.25-\mathrm{mmol}$ scale, using standard Fmoc (9-fluoroenylmethoxycarbonyl) chemistry, on a solid-phase peptide synthesizer (model 431A; Applied Biosystems, Foster City, CA). A cysteine was added to the $\mathrm{NH}_{2}$ terminus of pep- 


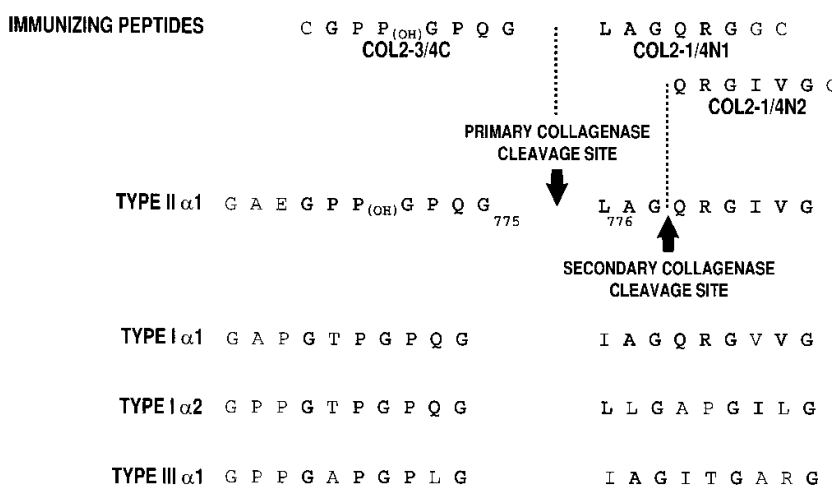

Figure 1. Sequence homology at and close to the interstitial collagenase cleavage sites of human type I, II, and III collagens and the immunizing peptides used to produce the COL2-3/4C, COL2-1/4N1, and COL2-1/4N2 antineoepitope antibodies. Bold letters indicate the amino acids in the alpha chains which are similar in both identity and location to those found in the natural immunizing peptide sequences, which are also highlighted by bold letters at the top of the figure. The primary collagenase cleavage sites were obtained from BirkedalHansen (50) while the secondary collagenase cleavage site was obtained by $\mathrm{NH}_{2}$ terminal sequencing of electrophoretically separated and transferred collagen fragments obtained after MMP-13 (rHuMMP-13) digestion of triple helical human type II collagen, as described in Methods. The assignment of hydroxylation of the proline residues in the immunizing peptides indicated as $\mathrm{P}_{(\mathrm{OH})}$, is also described in Methods.

tide COL2-3/4C and to the $\mathrm{COOH}$ termini of peptides COL2-1/4N1 and COL2-1/4N2 for conjugation of the peptides to the carrier proteins ovalbumin (OVA) and BSA using the bifunctional reagent $N$-hydroxy-succinimidyl bromoacetate (Sigma Chemical Co., St. Louis, MO), as described by Hughes et al. (39). A glycine spacer was included in the synthesis of the COL2-1/4N1 peptide, between the added $\mathrm{COOH}$ terminal cysteine and the neoepitope sequence, to improve both the immunogenicity of this peptide when conjugated to OVA and the sensitivity of the assays employing the peptide conjugated to BSA.

Preparation of polyclonal antibodies from rabbit antisera. For antineoepitope antisera production, female New Zealand White rabbits weighing 2.5-3.0 kg (Ferme des Chenes Bleues Inc., Montreal, Quebec, Canada) were initially immunized intramuscularly with $0.5 \mathrm{mg}$ of neoepitope peptide conjugated to OVA in $0.25 \mathrm{ml}$ PBS and emulsified with $0.25 \mathrm{ml}$ of CFA (Difco Laboratories, Inc., Detroit, MI). Booster injections of similar quantities of peptide-OVA emulsified with incomplete Freund's adjuvant (IFA; Difco Inc.) were given intramuscularly every 2-3 wk. After the second booster, test bleeds were performed and antibody titers were determined by ELISA, as described below. In all cases, good titers were obtained after the two boosters. Animals were exsanguinated by cardiac puncture and $\sim 50$ $\mathrm{ml}$ of serum was obtained. For immunoassays, $\mathrm{F}\left(\mathrm{ab}^{\prime}\right)_{2}$ preparations were obtained by pepsin digestion of each antiserum, as previously described (51). The Fc portion and undigested $\mathrm{IgG}$ were removed by AH-Sepharose-Protein A chromatography (Pharmacia Fine Chemicals, Uppsala, Sweden).

The preparation of a mouse monoclonal antibody (COL2-3/4m) to an intrachain epitope (CB11B) in the $\mathrm{TC}^{\mathrm{A}}$ of human type II collagen was described by us recently (6).

ELISAs for determining antibody titer and specificity. The immunizing peptides, conjugated to BSA, were diluted to $20 \mu \mathrm{g} / \mathrm{ml}$ in $0.1 \mathrm{M}$ carbonate buffer, $\mathrm{pH} 9.2$, and $50 \mu \mathrm{l}$ was added to each well $(1 \mu \mathrm{g} /$ well) of Immulon-2 flat-bottom tissue culture microtiter plates (Dy- natech Laboratories, Inc., Chantilly, VA). In other cases, plates were coated with $2 \mu \mathrm{g} /$ well of either native, heat-denatured, or MMP1-cleaved or MMP-13-cleaved human type I, II, III, and X collagens (see below). After $24 \mathrm{~h}$ at $4^{\circ} \mathrm{C}$, the plates were washed three times with PBS containing $0.1 \%$ vol/vol Tween 20 (PBS-Tween; Sigma Chemical Co.). Noncoated binding sites were blocked by $150 \mu \mathrm{l} /$ well of $1 \% \mathrm{wt} / \mathrm{vol}$ BSA in PBS (PBS-1\% BSA) for $30 \mathrm{~min}$ at room temperature. The plates were washed once with PBS-Tween and $50 \mu \mathrm{l}$ of serial dilutions of the appropriate polyclonal antiserum preparation were added to individual wells. After $90 \mathrm{~min}$ at $37^{\circ} \mathrm{C}$, the plates were washed three times with PBS-Tween. Alkaline phosphatase-conjugated goat anti-rabbit IgG (Sigma Chemical Co.) diluted 1:30,000 in PBS- $1 \%$ BSA-Tween was added at $50 \mu \mathrm{l} /$ well. After $1 \mathrm{~h}$ at $37^{\circ} \mathrm{C}$, the plates were washed three times with PBS-Tween and once with distilled water. Finally, $50 \mu \mathrm{l}$ of freshly prepared alkaline phosphatase substrate, disodium $p$-nitrophenyl phosphate (Sigma Chemical Co.) at $0.5 \mathrm{mg} / \mathrm{ml}$ in $8.9 \mathrm{mM}$ diethanolamine, $0.25 \mathrm{mM} \mathrm{MgCl}_{2}, \mathrm{pH} 9.8$ was added to each well for $20-30 \mathrm{~min}$ at $37^{\circ} \mathrm{C}$. The absorbances were measured at $405 \mathrm{~nm}$ on a plate reader (model Multiskan ${ }^{+}$MkII; ICN/ Flow, Mississauga, Ontario, Canada).

Inhibition ELISAs for analyses of type II collagen neoepitopes produced by collagenase cleavage. Linbro 96-well round bottom microtiter plates (ICN Flow) were precoated with $100 \mu \mathrm{l} /$ well of PBS-1\% BSA for $30 \mathrm{~min}$ at room temperature and washed once with PBSTween. Four nonspecific binding wells each contained $100 \mu \mathrm{l}$ of $50 \mu \mathrm{l}$ PBS- $1 \%$ BSA and $50 \mu \mathrm{l}$ PBS-1\% BSA-Tween. Each polyclonal $\mathrm{F}\left(\mathrm{ab}^{\prime}\right)_{2}$ antiserum preparation was diluted 1:200 in PBS-1\% BSATween (as determined by checkerboard analyses of antisera and peptide-BSA titrations, data not shown) and $50 \mu \mathrm{l}$ was added to each of the remaining wells of these preincubation plates. Four wells with antisera were mixed with $50 \mu \mathrm{l} /$ well of PBS- $1 \%$ BSA to determine maximum binding in the absence of the inhibitory epitopes. To the remaining test wells containing $50 \mu \mathrm{l}$ of diluted antiserum $\mathrm{F}\left(\mathrm{ab}^{\prime}\right)_{2}$ were added $50 \mu \mathrm{l} /$ well of appropriate dilutions of the standard peptides COL2-3/4C, COL2-1/4N1, or COL2-1/4N2; native, heat-denatured $\left(80^{\circ} \mathrm{C}\right.$ for $\left.20 \mathrm{~min}\right)$ or collagenase-cleaved type I, II, and III collagen solutions; concentrated (threefold) culture media from human OA articular cartilage explants; or $\alpha$-chymotrypsin extracts of human OA articular cartilage. For antibody specificity analyses, standard peptides containing the epitope that had been used for immunization were added, as described above, but with amino acid residues either added to $(+1,+2,+3)$ or removed from $(-1,-2,-3)$ the end of the immunizing peptide corresponding to the cleaved terminus of the $\alpha$ chain fragment. Also, two overlapping 16mer peptides representing the amino acid sequence bridging the primary and secondary collagenase cleavage sites of native type II collagen (Gly-Pro-Hyp-Gly-ProGln-Gly-Leu-Ala-Gly-Gln-Arg-Gly-Ile-Val-Gly and Gly-Pro-Gln-GlyLeu-Ala-Gly-Gln-Arg-Gly-Ile-Val-Gly-Leu-Hyp-Gly) were used to demonstrate the specificity of the immunoreactivities of the antisera to the cleaved termini and not to intact $\alpha$ chains at the cleavage sites. All standards and samples were tested in duplicate wells. Analyses were always repeated at least once.

After incubation for $1 \mathrm{~h}$ at $37^{\circ} \mathrm{C}, 50 \mu \mathrm{l}$ of each preincubated sample was transferred to the equivalent wells of Immulon-2 ELISA plates, precoated, as described above, with neoepitope peptide-BSA conjugates diluted to $50 \mathrm{ng} /$ well for COL2-3/4C, $150 \mathrm{ng} /$ well for COL2-1/4N1, and $120 \mathrm{ng} /$ well for COL2-1/4N2, all in PBS, pH 7.2. Note that for the COL2-3/4C assay, the BSA-conjugate used to coat the plates contained the peptide Cys-Gly-Gly-Glu-Gly-Pro-Hyp-GlyPro-Gln-Gly (COL2-3/4C long), which included the natural in-sequence amino acid residue (Glu) and two glycine spacers added to the $\mathrm{NH}_{2}$ terminus of the immunizing COL2-3/4C peptide. In preliminary experiments, the use of this longer peptide was found to increase the sensitivity of the COL2-3/4C assay over that obtained by using the shorter immunizing peptide-BSA conjugate (data not shown). These plates were incubated for $30 \mathrm{~min}$ at $4^{\circ} \mathrm{C}$ and then washed three times with PBS-Tween. Goat anti-rabbit IgG F $\left(\mathrm{ab}^{\prime}\right)_{2}$ fragment conjugated to alkaline phosphatase (Sigma Chemical Co.) was diluted 1:20,000 in 
PBS- $1 \%$ BSA-Tween and added at $50 \mu \mathrm{l} /$ well. After incubation for $1 \mathrm{~h}$ at $37^{\circ} \mathrm{C}$, the plates were washed three times with PBS-Tween and three times with distilled water. From an ELISA amplification system kit (GIBCO BRL, Gaithersburg, MD), $50 \mu l$ of amplifier substrate (NADPH) was added to each well and after $15 \mathrm{~min}$ at room temperature, $50 \mu \mathrm{l}$ of amplifier (alcohol dehydrogenase and diaphorase) solution was added to each well. After a final $15 \mathrm{~min}$ at room temperature, the color development was halted with $50 \mu \mathrm{l}$ of $0.3 \mathrm{M} \mathrm{H}_{2} \mathrm{SO}_{4}$ and the absorbance was measured at $490 \mathrm{~nm}$. For each plate the mean absorbance from the four nonspecific binding wells was subtracted from the absorbance values of each of the other wells. The percentage inhibition of binding by standards or samples were calculated relative to the mean absorbance from the four maximum binding wells which represented $0 \%$ inhibition ( $100 \%$ binding). Results were also expressed on a molar basis using a molecular weight for type II $\alpha$ chain of 98,291 D (6) and for the COL2-3/4C peptide of $608 \mathrm{D}$.

Proteolytic cleavage of native type I, II, and III collagens by human recombinant collagenases MMP-1, MMP-8, and MMP-13. Lyophilized human type I, II, and III collagens were dissolved in $0.5 \mathrm{M}$ acetic acid and then diluted to a final concentration of $2.5 \mathrm{mg} / \mathrm{ml}$ in digestion buffer consisting of $50 \mathrm{mM}$ Tris, $10 \mathrm{mM} \mathrm{CaCl}_{2}, 0.5 \mathrm{M} \mathrm{NaCl}$, $0.01 \%$ Brij 35 (Sigma Chemical Co.) and $0.02 \% \mathrm{NaN}_{3}$, pH 7.6. Recombinant human proenzymes MMP-1 (rHuMMP-1), MMP-8 (rHuMMP-8), and MMP-13 (rHuMMP-13) were activated by incubation with $2 \mathrm{mM}$ (final concentration) aminophenyl mercuric acetate (APMA; Sigma Chemical Co.) in the same digestion buffer for 90 min at $37^{\circ} \mathrm{C}$. Each activated enzyme solution was added to individual collagen solutions at a final molar ratio of collagenase to collagen of 1:5 (MMP-1 or MMP-8/collagen) or 1:10 (MMP-13/collagen). Where necessary, the $\mathrm{pH}$ was adjusted to 7.5. Controls contained collagen in digestion buffer with $2 \mathrm{mM}$ APMA but with no collagenase.

For immunoanalyses by ELISA of cleavage neoepitopes, the samples were incubated for $24 \mathrm{~h}$ at $30^{\circ} \mathrm{C}$ and then the rHuMMPs were inactivated by the addition of $20 \mathrm{mM}$ (final concentration) EDTA (Sigma Chemical Co.). For studies of time-dependent collagenase cleavage of native type II collagen, aliquots were removed at times indicated in the figure legends, over $72 \mathrm{~h}$ of digestion at $30^{\circ} \mathrm{C}$ and the collagenase was inactivated with EDTA.

Electrophoresis and immunoblotting. SDS-PAGE of MMP-1, MMP-8, and MMP-13 cleaved purified native human collagens were performed as previously described (52) under denaturing conditions using 10\%, 1-mm thick, $7 \times 8 \mathrm{~cm}$ mini-Protean gels stained with Coomassie Blue R-250 (Bio-Rad Laboratories, Mississauga, Ontario, Canada) in $40 \% \mathrm{vol} / \mathrm{vol}$ methanol and $10 \% \mathrm{vol} / \mathrm{vol}$ acetic acid in distilled water. Electrophoretic transfers to nitrocellulose membranes (Bio-Rad) were performed as previously described (5), with the following exceptions. The PBS-3\% BSA blocked membranes were incubated overnight at $4{ }^{\circ} \mathrm{C}$ with either anti-COL2-3/4C or anti-COL2-1/ $4 \mathrm{~N} 1$ or anti-COL2-1/4N2 $\mathrm{F}\left(\mathrm{ab}^{\prime}\right)_{2}$ preparations diluted 1:200 in PBS-3\% BSA-Tween. After three 10-min washes in PBS-1\% BSA-Tween, the membranes were incubated for $1 \mathrm{~h}$ at room temperature with alkaline phosphatase-conjugated goat anti-rabbit IgG $\mathrm{F}\left(\mathrm{ab}^{\prime}\right)_{2}$ fragment diluted 1:30,000 with PBS-3\% BSA-Tween. The membranes were given $3 \times 10$ min washes in PBS-1\% BSA-Tween and then rinsed well in distilled water, before adding alkaline phosphatase substrate solution from a commercial kit (Bio-Rad) using 5-bromo-4-chloro-3-indolyl phosphate and nitroblue tetrazolium. After optimal color development (10-20 $\mathrm{min})$, the reaction was stopped by washing off the substrate solution with distilled water.

Extraction of human articular cartilage for the measurement of collagenase-cleaved, denatured, and total type II collagen contents. Preliminary studies using MMP-1 and MMP-13 cleaved human type II collagens (not shown) established that the levels of the COL2-3/4C neoepitope, as detected by ELISA, were not significantly affected by $\alpha$-chymotrypsin treatment under the conditions previously described to extract denatured collagen from articular cartilage (6). Therefore, femoral condylar articular cartilages from 19 normal and 26 osteoarthritic joints were diced and incubated overnight at $37^{\circ} \mathrm{C}$ with $1.0 \mathrm{mg} /$
50-75 mg cartilage of $\alpha$-chymotrypsin in $50 \mathrm{mM}$ Tris- $\mathrm{HCl}, \mathrm{pH} 7.6$ (with the proteinase inhibitors: $1 \mathrm{mM}$ EDTA, $1 \mathrm{mM}$ iodoacetamide, and $10 \mu \mathrm{g} / \mathrm{ml}$ pepstatin A; Sigma Chemical Co.). The $\alpha$-chymotrypsin activity was inhibited with $20 \mu \mathrm{l}(160 \mu \mathrm{g} / \mathrm{ml}$ final concentration) of $N$-tosyl-L-phenylalanine-chloromethyl ketone (TPCK; Sigma Chemical Co.). After $20 \mathrm{~min}$ at $37^{\circ} \mathrm{C}$, the samples were centrifuged and the supernatants were removed and assayed for the COL2-3/4C neoepitope (as described above) and COL2-3/4m hidden epitope (6). The remaining cartilage residues were digested overnight at $56^{\circ} \mathrm{C}$ with 1.0 $\mathrm{mg} / \mathrm{ml}$ proteinase $\mathrm{K}$ in Tris solution containing the same proteinase inhibitors and then boiled for $20 \mathrm{~min}$ to denature the enzyme. Total type II collagen content of each sample was determined from the collective amount of COL2-3/4m epitope in both the $\alpha$-chymotrypsin extract and the proteinase $\mathrm{K}$ digestion. The percent denatured collagen was determined from the amount of COL2-3/4m epitope in the $\alpha$-chymotrypsin extract expressed as a percentage of the total collagen content. The percent cleaved collagen was calculated from the amount of COL2-3/4C neoepitope assayed in the $\alpha$-chymotrypsin extract expressed as a percentage of the total collagen content.

Mankin grading. Frozen sections that were prepared for extraction immunoassay were stained with Safranin $\mathrm{O}$ and Fast Green and were graded for degenerative changes as described by Mankin et al. (53). The maximum grade was 13 , as there was no calcified cartilage in the specimens used.

Human $O A$ articular cartilage explant cultures. Full-depth human femoral condylar articular cartilages in serum-free culture media (see below) were removed from the subchondral bone within $6 \mathrm{~h}$ of its removal from three OA patients undergoing joint replacement surgery. The cartilage was diced into $\sim 1-\mathrm{mm}^{3}$ pieces and placed for $1 \mathrm{~h}$ in basic culture medium consisting of DME with $3.6 \mathrm{mg} / \mathrm{ml}$ of Hepes (GIBCO BRL), $100 \mathrm{U} / \mathrm{ml}$ penicillin and $100 \mu \mathrm{g} / \mathrm{ml}$ streptomycin to which was added $2.5 \mu \mathrm{g} / \mathrm{ml}$ amphotericin B (Fungizone; GIBCO BRL). It was then transferred to the same basic culture medium (DMEHepes) containing $1,000 \mathrm{U} / \mathrm{ml}$ penicillin and $1 \mathrm{mg} / \mathrm{ml}$ streptomycin for $30 \mathrm{~min}$. After a final wash in basic culture medium, $40-50 \mathrm{mg}$ wet weight of cartilage was transferred to each well of a 24-well tissue culture plate (Falcon Labware, Becton Dickinson \& Co., Lincoln Park, NJ) containing $1 \mathrm{ml} /$ well of basic culture medium supplemented with 1 $\mathrm{mg} / \mathrm{ml} \mathrm{BSA} \mathrm{(Sigma} \mathrm{Chemical} \mathrm{Co.),} 50 \mu \mathrm{g} / \mathrm{ml} \mathrm{L}$-ascorbic acid (Sigma Chemical Co.), and $5 \mu \mathrm{g} / \mathrm{ml}$ insulin, $5 \mu \mathrm{g} / \mathrm{ml}$ transferrin, and $5 \mathrm{ng} / \mathrm{ml}$ sodium selenite (ITS; Boehringer Mannheim, Mannheim, Germany). The cartilage was precultured for four days at $37^{\circ} \mathrm{C}, 5 \% \mathrm{CO}_{2}$ and $95 \%$ relative humidity. The media were removed and quadruplicate samples were cultured either in the basic culture medium (+ BSA, ascorbic acid, ITS; Boehringer Mannheim) supplemented with 10, 2.5, and 1.0 nM of RS 102,481 (Roche Bioscience, Palo Alto, CA), a synthetic, preferential MMP-13, carboxylate inhibitor $\left(\mathrm{K}_{\mathrm{i}}[\mathrm{nM}]: 1,100\right.$, MMP-1; 32, MMP-2; 19, MMP-3; 18, MMP-8; 0.08, MMP-13) in $0.1 \%$ DMSO, or in medium with only $0.1 \%$ DMSO, the inhibitor vehicle. Media and inhibitors were replaced every $2 \mathrm{~d}$ of culture and the conditioned media were frozen at $-20^{\circ} \mathrm{C}$ until assayed for the COL2-3/ $4 \mathrm{C}$ neoepitope (as described above). Cultures were terminated after $12 \mathrm{~d}$. The experiment was repeated twice with the articular cartilage from two other patients.

The measurement of total collagen synthesis. To determine the effect of inhibitor RS 102,481 on type II collagen synthesis, explants of human OA articular cartilage were cultured as described above, with or without the highest concentration $(10 \mathrm{nM})$ of inhibitor. On days 14,16 , and 18 of culture, $15 \mu \mathrm{Ci}$ of $\left[{ }^{3} \mathrm{H}\right]$ proline was added to each $\mathrm{ml}$ of medium. The conversion of radiolabeled proline into tritiated hydroxyproline within the explants, as an indicator of type II collagen synthesis, was determined after day 20 in two independent cultures, using the method described by Tyler and Benton (54).

Statistical analysis. Spearman rank correlations were used for analyzing relationships between different parameters used in the study. Mann-Whitney U tests were used to compare the nonarthritic (normal) and OA groups, in terms of the collagenase-generated neoepitopes detected by immunoassay. 
A

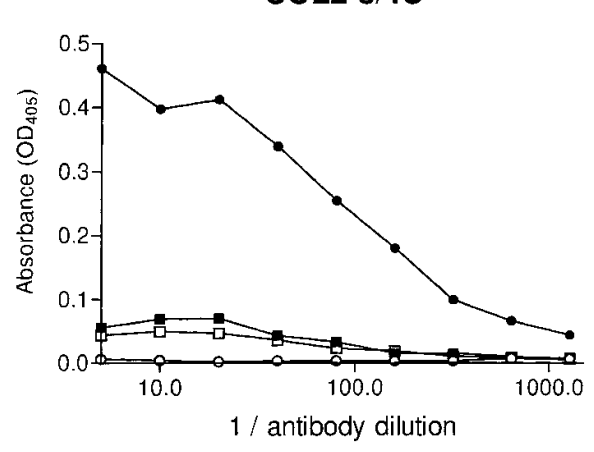

B

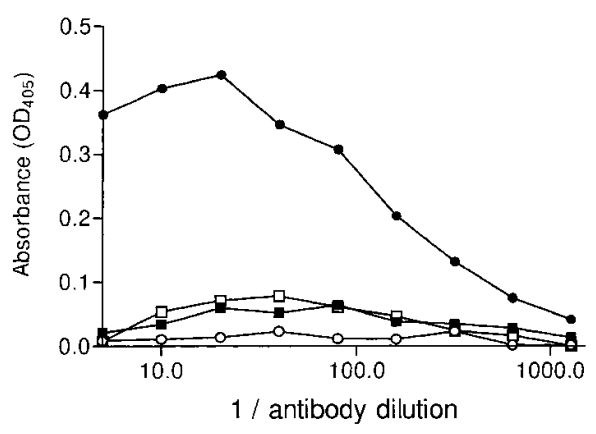

C

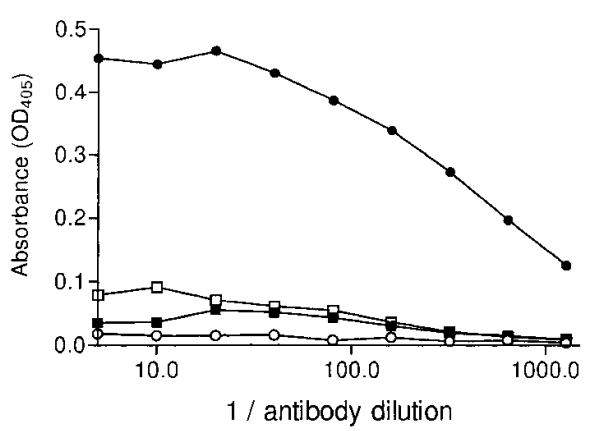

Figure 2. Immunoreactivities of collagenase antineoepitope $\mathrm{F}\left(\mathrm{ab}^{\prime}\right)_{2}$ antibody subunits with immunizing peptides and human type II collagen as determined by direct-binding ELISAs. Immulon-2 microtiter plates were coated with $1 \mu \mathrm{g} /$ well of each of the immunizing peptides conjugated to BSA (-). As well, plates were coated with $1 \mu \mathrm{g} / \mathrm{well}$ of BSA $(\bigcirc)$ or $2 \mu \mathrm{g} /$ well of either triple helical $(\square)$ or heat-denatured $\left(80^{\circ} \mathrm{C}\right.$ for $\left.20 \mathrm{~min}\right)(\square)$ human type II collagens. After blocking unbound sites with BSA, serial dilutions of the collagenase antineoepitope $\mathrm{F}\left(\mathrm{ab}^{\prime}\right)_{2}$ preparations (in PBS-1\% BSA-Tween [from 1:5 to 1:1280]) were added in duplicate to the wells of their respective plates and processed as described in Methods. Shown are the results of the ELISAs for the COL2-3/4C $(A)$, COL2-1/4N1 $(B)$, and COL2$1 / 4 \mathrm{~N} 2(C) \mathrm{F}\left(\mathrm{ab}^{\prime}\right)_{2}$ preparations.

\section{Results}

Polyclonal antibodies to mammalian collagenase-generated neoepitopes of $\alpha 1$ (II) collagen $T C^{A}$ and $T C^{B}$

Direct-binding ELISAs for determination of antibody titers. Sera obtained from rabbits immunized with OVA conjugates of the neoepitope peptides and $\mathrm{F}\left(\mathrm{ab}^{\prime}\right)_{2}$ preparations of these sera were initially characterized by direct binding ELISAs. In the immunochemical analyses, the $\mathrm{F}\left(\mathrm{ab}^{\prime}\right)_{2}$ preparations were used to ensure specific binding. Each of the antineoepitope antibodies reacted similarly with its own immunizing peptide (Fig. 2) which was conjugated to BSA and bound to the microtiter plates to improve immunoreactivity. None of the antibodies showed any significant immunoreactivity to BSA, native or heat-denatured human type II collagen (Fig. 2), or native or heat-denatured human type I, III, and X collagens (data not shown).

Inhibition ELISAs for neoepitope characterization. A panel of nonconjugated peptides with amino acid additions to $(+1$, $+2,+3)$ and deletions from $(-1,-2,-3)$ either the $\mathrm{COOH}$ terminus of COL2-3/4C or the $\mathrm{NH}_{2}$ termini of COL2-1/4N1 and COL2-1/4N2 immunizing peptides were prepared. These were used in competitive ELISAs to determine the specific amino acid sequences recognized by each antibody and thereby verify that they were indeed antineoepitope antibodies. Removal or addition of one residue resulted in a loss of inhibition ranging from 80 to $100 \%$, depending upon the peptide concentration, for the COL2-3/4C antibody (Fig. $3 \mathrm{~A}$ ) and complete loss of inhibition for the COL2-1/4N2 antibody (Fig. $3 \mathrm{~B}$ ). For the COL2-1/4N1 antibody, it was only after three amino acids were deleted from the $\mathrm{NH}_{2}$ terminus (which is then the $\mathrm{NH}_{2}$ terminus of the COL2-1/4N2 peptide) that there was a complete loss of inhibition (Fig. $3 C$ ). This is significant in that it shows that the COL2-1/4N1 antibody will not recognize the amino acids comprising the $\mathrm{NH}_{2}$ terminus of the secondary cleavage site produced by mammalian collagenases (Fig. 1).

The two 16mer overlapping peptides designed to represent the amino acid sequences bridging both the primary and secondary collagenase cleavage sites of type II collagen $\alpha 1$ chains did not significantly inhibit any of the antibodies (data not shown).

Inhibition ELISAs using antibodies to COL2-3/4C neoepitope demonstrating comparative reactivity to immunizing peptide and collagenase-cleaved and uncleaved fibrillar collagens

To further validate the specificity of the antibodies to the COL2-3/4C neoepitope, complete digests by MMP-1 and MMP-13 of collagen (verified by Coomassie staining of SDSPAGE gels) and heat-denatured type I, II, and III collagen solutions at concentrations of 29, 58, 115, 230, 460, and $920 \mu \mathrm{g} / \mathrm{ml}$ were examined in inhibition ELISAs along with the nonconjugated COL2-3/4C immunizing peptide. Typical standard curves plotted as the percent inhibition against log of the competing antigen concentration $(\mu \mathrm{g} / \mathrm{ml})$ are shown in Fig. $4 A$. Heatdenatured type I and II collagens showed no reactivity. Otherwise, positive immunoreactivity always exhibited excellent parallelity for each analysis. On a molar basis, the inhibition was very similar for MMP-1 and MMP-13 cleaved type II collagens and the COL2-3/4C peptide (Fig. $4 \mathrm{~B}$ ). The $\mu \mathrm{M}$ concentration of the COL2-3/4C epitope was calculated as described in Methods. Although there was parallelity between both the MMP-1 and MMP-13 cleaved type I collagen solutions and the COL2- 
A

COL $2 \cdot 3 / 4 \mathrm{C}$ (short)

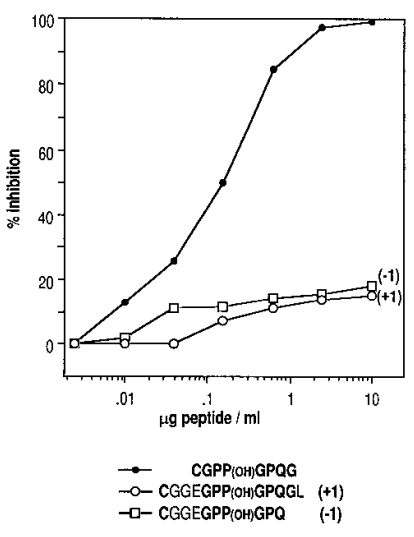

B

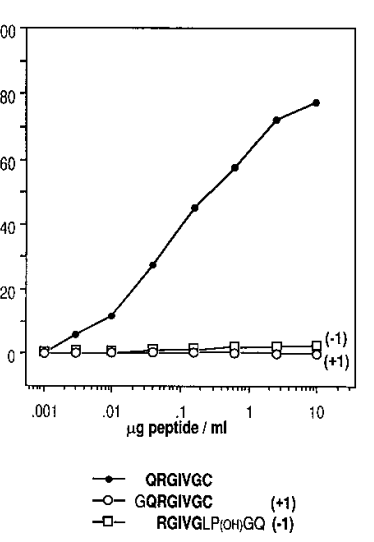

C

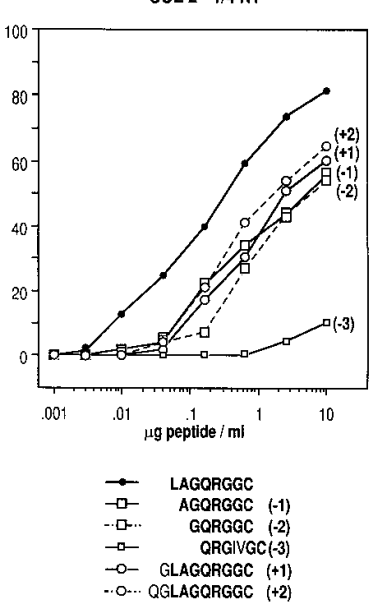

Figure 3. Epitope specificities of the antineoepitope antisera determined using competing synthetic peptides in inhibition ELISAs. Varying dilutions of the nonconjugated immunizing peptides $(\bullet)$ were added to 1:200 dilutions of their respective $\mathrm{F}\left(\mathrm{ab}^{\prime}\right)_{2}$ preparations in 96 -well round bottom microtiter plates for $1 \mathrm{~h}$ at $37^{\circ} \mathrm{C}$. Then $50 \mu \mathrm{l}$ was transferred from each well to the equivalent wells of Immulon-2 microtiter plates precoated with the respective immunizing peptides conjugated to BSA. The plates were then processed as described in Methods for the development of a standard inhibition curve for each neoepitope antiserum. For the COL2-3/4C $(A)$ and the COL2-1/4N2 $(B)$ antibodies, shown are the results of ELISAs performed with synthetic peptides that had either 1 amino acid added to $(\bigcirc)$ or deleted from $(\square)$ the end of the immunizing peptide corresponding

to the cleaved termini of the alpha chain fragments. The sequences of these peptides are shown in the individual legends for each antineoepitope antiserum. For the COL2-1/4N1 antibody $(C)$, residues were either added to (open circles) or deleted from (open squares) the $\mathrm{NH}_{2}$ terminus of the immunizing peptide. It was only when three residues were deleted from the $\mathrm{NH}_{2}$ terminus $(\square)$ of the COL2-1/4N1 peptide and not one residue, as for the COL2-3/4C and COL2-1/4N2 peptides, that there was a complete loss of inhibition with the COL2-1/4N1 antibody.

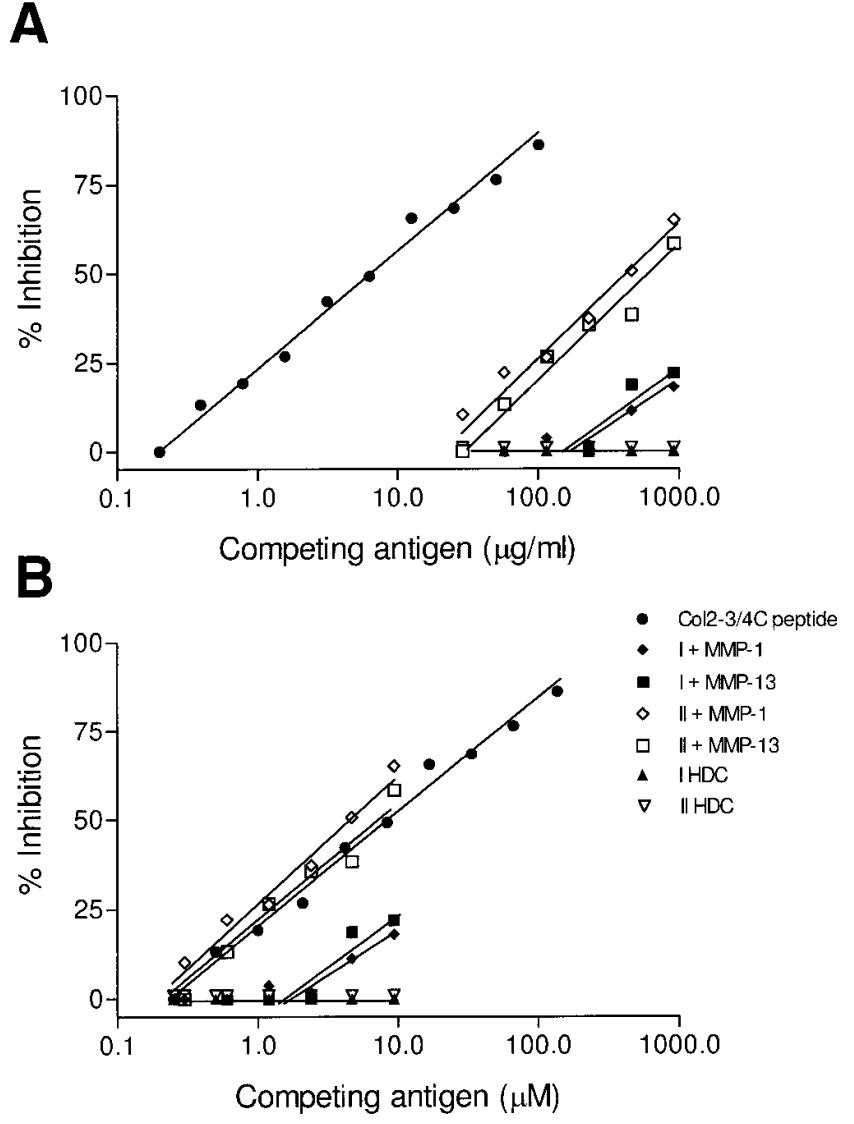

Figure 4. ELISA to show specificity of the COL2-3/4C antibody for the $\mathrm{COOH}$ terminal neoepitope of $\alpha 1$ (II) collagen chains created by the digestion of triple helical type II collagen by the collagenases MMP-1 and MMP-13. Heat-denatured and collagenase-cleaved (MMP-1 and MMP-13) human type I, II, and III collagens (digestions were complete as shown by Coomassie staining of SDS-PAGE gels)
3/4C peptide, the cleaved type II collagen was much more inhibitory than the cleaved type I collagen (Fig. $4 \mathrm{~B}$ ). This may in part be due to the fact that the sequence in human type I and II collagen $\alpha$ chains for the five residues amino-terminal to the cleavage site is identical. We do not yet know how important hydroxylation is at $\mathrm{PrO}_{771}$, nor do we know how important the threonine residue is at position 770 in the type I collagen $\alpha 1$ and $\alpha 2$ chains, which is a proline residue in the type II $\alpha 1$ chains. Studies are in progress to address these issues. Neither the MMP-cleaved nor the heat-denatured type III collagen solutions showed inhibition (data not shown). The COL2-3/4C peptide was used as the standard in all subsequent ELISAs. Similar analyses for the antibodies to the COL2-1/4N2 epitope are not shown because they were not used in immunoassays in this study.

MMP-1, MMP-8, and MMP-13 produce sequential cleavages in type II collagen

Acid-soluble human type II collagen was cleaved with MMP-1 for up to $72 \mathrm{~h}$, with aliquots removed and inactivated by the addition of EDTA at time 0, 0.5, 1, 3, 5, 24, 48, and $72 \mathrm{~h}$. There was almost complete cleavage of the $\alpha 1$ (II) chains by $5 \mathrm{~h}$, as shown by Coomassie staining of SDS-PAGE separated digests (Fig. $5 \mathrm{~A}$ ). All the antineoepitope antibodies reacted with their

were assayed in inhibition ELISAs at concentrations of 20,58, 115 , 230,460 , and $920 \mu \mathrm{g} / \mathrm{ml}$ of digestion buffer. A standard curve for the COL2-3/4C peptide $(\bullet)$ was also constructed using doubling dilutions from 50 to $0.1 \mu \mathrm{g}$ of the peptide/ml of buffer in the same inhibition ELISA. Shown are typical standard curves plotted as percent inhibition against the log of the competing antigen concentrations as $\mu \mathrm{g} / \mathrm{ml}(A)$ and on a $\mu \mathrm{M}$ basis $(B)$. Symbols show MMP-1 $(\diamond, \diamond)$ and MMP-13 $(\mathbf{\square}, \square)$ cleaved type I and type II collagens, respectively, and heat-denatured type I (I HDC; $\mathbf{\Lambda}$ ) and type II (II HDC; $\nabla$ ) collagens. 

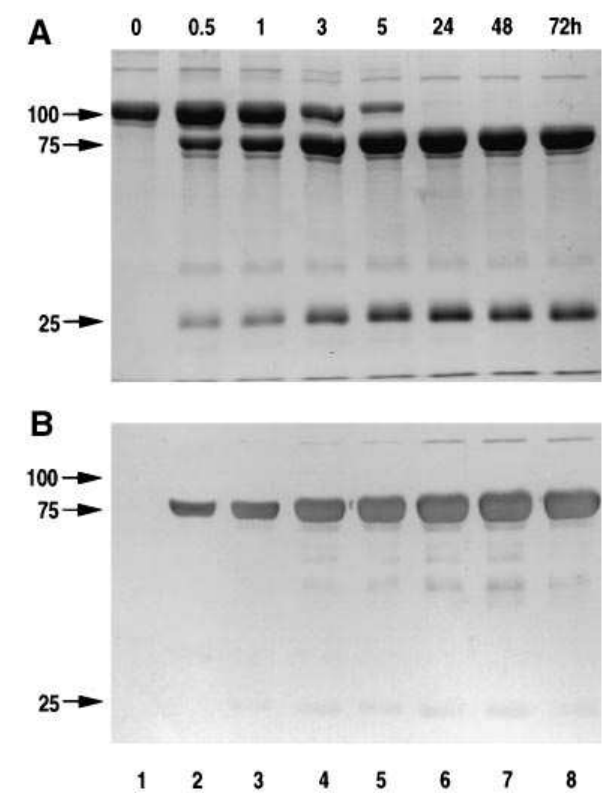

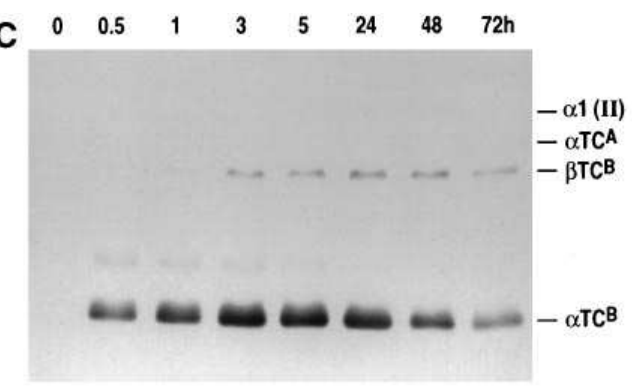

D

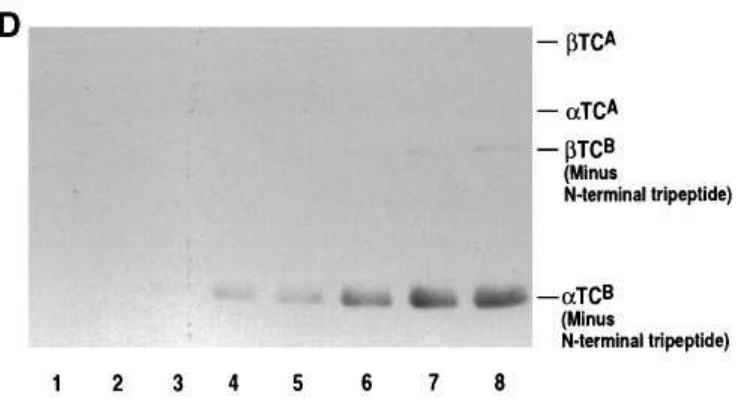

Figure 5. Time course of cleavage of triple helical human type II collagen by rHuMMP-1. Purified human type II collagen was solubilized in digestion buffer and incubated at $30^{\circ} \mathrm{C}$ for $72 \mathrm{~h}$ with APMA-activated rHuMMP-1 at a final molar ratio of 1:5 (MMP-1:collagen). Aliquots were removed at $0,0.5,1,35,24,48$, and $72 \mathrm{~h}$ and the MMP-1 was inactivated in each sample by the addition of $20 \mathrm{mM}$ EDTA (final concentration). The samples were separated under reducing conditions with SDS-PAGE

$(10 \%)$ and either stained with Coomassie Blue $(A)$ or electrophoretically transferred to nitrocellulose and incubated overnight with

1:200 dilutions in PBS-3\% BSA-Tween of COL2-3/4C $(B)$, COL2-1/4N1 $(C)$, and COL2-1/4N2 $(D)$ antineoepitope F(ab' $)_{2}$ preparations. Shown are undigested type II collagen (lane 1); type II collagen + APMA-activated MMP-1 for 0.5 (lane 2), 1 (lane 3), 3 (lane 4), 5 (lane 5), 24 (lane 6), 48 (lane 7), and 72 (lane 8 ) h. Right margin indicates the positions of $\alpha 1$ (II) chains and the single $\left(\alpha \mathrm{TC}^{\mathrm{A}}\right)$ and dimeric $\left(\beta \mathrm{CC}^{\mathrm{A}}\right)$ forms of TC $\mathrm{And}^{\mathrm{A}}$ the single $\left(\alpha \mathrm{TC}^{\mathrm{B}}\right)$ and dimeric $\left(\beta \mathrm{TC}^{\mathrm{B}}\right)$ forms of $\mathrm{TC}^{\mathrm{B}}$ alpha chain fragments produced by MMP-1 cleavage of intact type II collagen. Left margin indicates the estimated molecular weights of the intact $\alpha 1(\mathrm{II})$ chains $(100 \mathrm{kD})$ and $\alpha \mathrm{TC}^{\mathrm{A}}(75 \mathrm{kD})$ and $\alpha \mathrm{TC} \mathrm{B}^{\mathrm{B}}(25 \mathrm{kD})$ of type II collagen.

respective cleaved fragments but showed no reactivity with $\alpha$ chains on Western blot analyses. The COL2-3/4C antibody stained both the single $\left(\alpha \mathrm{TC}^{\mathrm{A}}\right)$ and dimeric $\left(\beta \mathrm{TC}^{\mathrm{A}}\right) \alpha$ chain fragments created by MMP-1 cleavage of type II collagen with increasing intensity up to $48 \mathrm{~h}$ (Fig. $5 \mathrm{~B}$ ). The COL2-1/4N1 antibody stained both the single $\left(\alpha \mathrm{TC}^{\mathrm{B}}\right)$ and dimeric $\left(\beta \mathrm{TC}^{\mathrm{B}}\right)$ fragments with increasing intensity up to $5 \mathrm{~h}$ and progressively declined thereafter (Fig. 5 C). Moreover, the COL2-1/4N2 antibody first stained $\mathrm{TC}^{\mathrm{B}}$ weakly at $3 \mathrm{~h}$ and then with increasing intensity up to $72 \mathrm{~h}$ as the neoepitope COL2-1/4 N1 disappeared (Fig. $5 \mathrm{D}$ ). This demonstrated a loss of the primary collagenase cleavage site neoepitope (COL2-1/4N1) and the appearance of the secondary cleavage site neoepitope (COL2-1/ 4N2) with MMP-1 digestion of type II collagen. This was confirmed by microsequencing (data not shown).

Type II collagen cleavage by MMP- 8 was generally slower under the conditions of this study and the complete cleavage of $\alpha 1$ (II) chains occurred only after $24 \mathrm{~h}$ of digestion (Fig. $6 A$ ).
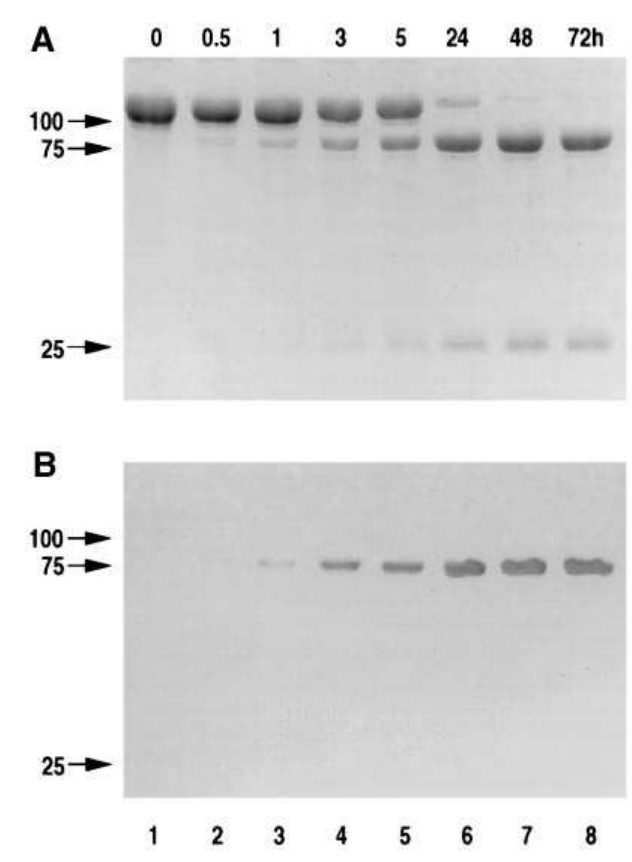

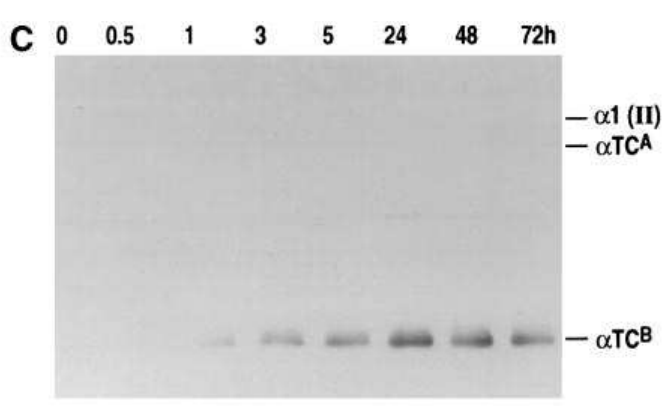

D

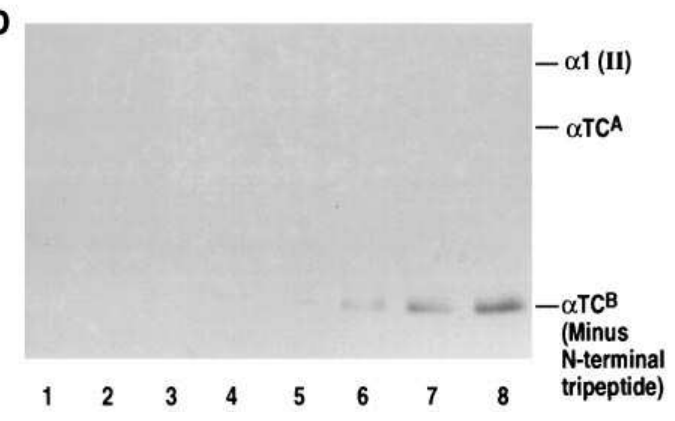

Figure 6. Time course of cleavage of triple helical human type II collagen by rHuMMP-8. The methodology used was as described for the rHuMMP-1 digestion. After SDS-PAGE (10\%), gels were stained with Coomassie Blue $(A)$ or the separated proteins were transferred to nitrocellulose and incubated overnight with 1:200 dilutions in PBS-3\% BSA-Tween of COL2-3/4C $(B)$, COL2-1/4N1 $(C)$, or COL2-1/4N2 $(D)$ antineoepitope $\mathrm{F}\left(\mathrm{ab}^{\prime}\right)_{2}$ preparations. Lanes and margins are as described in Fig. 5. 

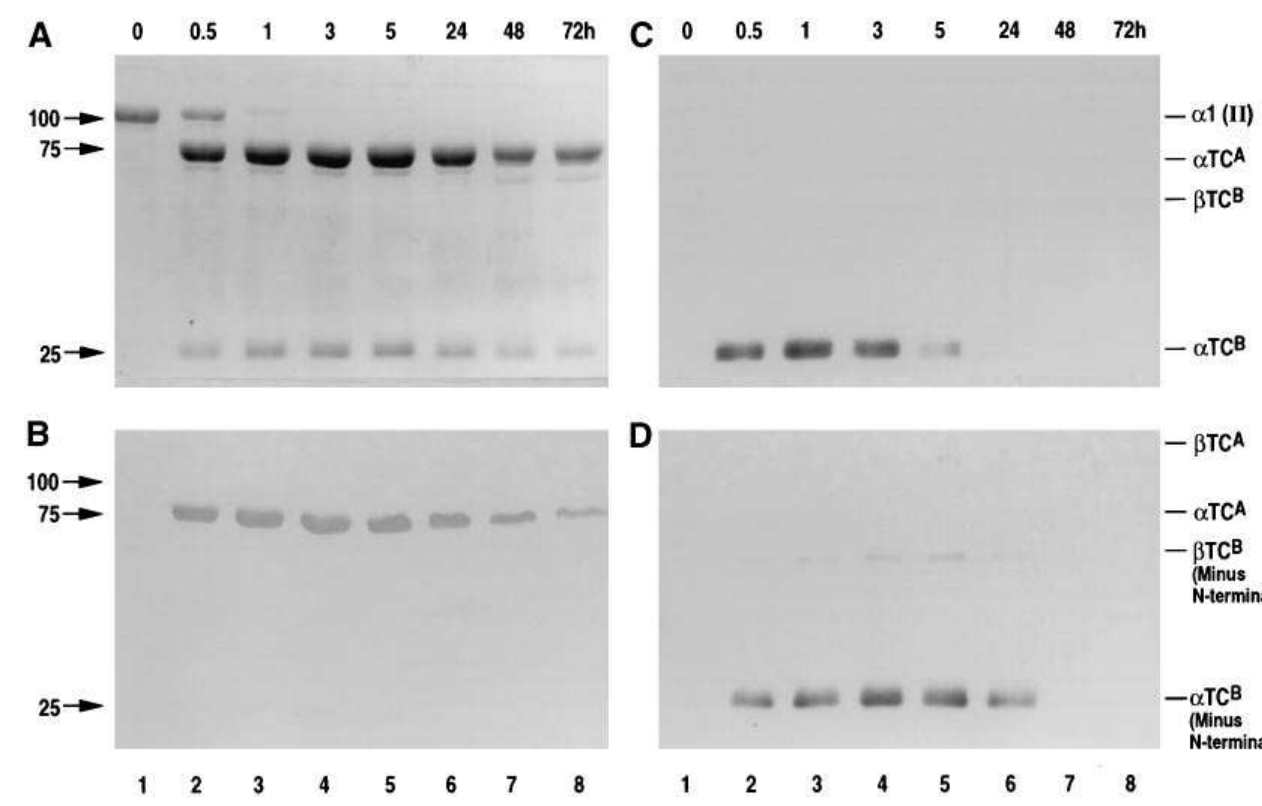

Figure 7. Time course of cleavage of triple helical human type II collagen by recombinant human MMP (rHuMMP-13). The methodology used was as described for rHuMMP-1 digestion (see legend, Fig. 5), except that a final molar ratio of 1:10 for MMP-13:collagen was used. After SDS-PAGE $(10 \%)$, gels were stained with Coomassie Blue $(A)$ or the separated proteins were transferred to nitrocellulose and incubated overnight with 1:200 dilutions in PBS-3\% BSA-Tween of COL2-3/4C (B), COL2-1/4N1 $(C)$, or COL2-1/4N2 $(D)$ antineoepitope $\mathrm{F}\left(\mathrm{ab}^{\prime}\right)_{2}$ preparations. Lanes and margins are as described in Fig. 5.
The COL2-3/4C antibody stained $\mathrm{TC}^{\mathrm{A}}$ on Western blot analysis with increasing intensity up to $72 \mathrm{~h}$ (Fig. $6 \mathrm{~B}$ ). The COL2-1/ $4 \mathrm{~N} 1$ antibody stained $\mathrm{TC}^{\mathrm{B}}$ with increasing intensity up to $24 \mathrm{~h}$ and then progressively declined thereafter (Fig. $6 \mathrm{C}$ ). The COL2$1 / 4 \mathrm{~N} 2$ antibody stained $\mathrm{TC}^{\mathrm{B}}$ with increasing intensity from 5-72 h, as the staining intensity for the COL2-1/4N1 neoepitope weakened (Fig. $6 \mathrm{D}$ ).

The primary cleavage of the $\alpha 1$ (II) chains by MMP-13 was much faster than that by MMP-1 or MMP-8 and was almost complete after only $30 \mathrm{~min}$ (compare Fig. $7 A$ with Fig. $5 A$ and Fig. $6 A$ ), confirming the results of recent studies comparing the rates of cleavage of type II collagens by MMP-1 and MMP-13 (10, 14, 26). The primary cleavage site neoepitope (COL2-3/4C) was reduced in content after only $5 \mathrm{~h}$ digestion indicating further cleavage of $\mathrm{TC}^{\mathrm{A}}$ (Fig. $7 \mathrm{~B}$ ). Moreover, the $\mathrm{NH}_{2}$ terminal primary cleavage site neoepitope (COL2-1/4N1) increased up to $1 \mathrm{~h}$ but was then reduced and had disappeared after $3 \mathrm{~h}$ (Fig. $7 \mathrm{C}$ ). In contrast, the secondary cleavage site neoepitope (COL2-1/4N2) was detectable within $30 \mathrm{~min}$ and increased up to $5 \mathrm{~h}$ before decreasing. After $24 \mathrm{~h}$, it was no longer detectable (Fig. $6 \mathrm{D}$ ).

This secondary cleavage produced by MMP-13 was recently described through the $\mathrm{NH}_{2}$ terminal sequencing of MMP-13 cleaved human type II collagen $\mathrm{TC}^{\mathrm{B}}$ (14). To confirm this loss of the COL2-1/4N1 neoepitope (Fig. 7 C), the MMP-13 digestion samples used for this immunoblot were assayed in an inhibition ELISA and no detectable COL2-1/4N1 epitope was found after $5 \mathrm{~h}$ of MMP-13 cleavage (data not shown). It is worth noting that the percentage recovery of this neoepitope, based on the amount of epitope present in the intact collagen, reached a maximum of only $21 \%$ after $60 \mathrm{~min}$. This suggests a rapid removal of the $\mathrm{NH}_{2}$ terminal Leu-Ala-Gly tripeptide from $\mathrm{TC}^{\mathrm{B}}$. Further studies are in progress to compare, by immunoassay, the relative rates of digestion of type II and other collagens by MMP-1, MMP-8, and MMP- 13 .

None of the antibodies recognized the cyanogen bromide generated CB10 peptides of human type II collagen, which contain the intact collagenase cleavage site of triple helical col- lagen $\alpha 1(\mathrm{II})$ chains (data not shown). This supports the ELISA results described above showing nonreactivity of the neoepitope antisera for 16 mer synthetic peptides representing the amino acid sequences bridging the primary and secondary collagenase cleavage sites in human type II collagen. Together these results confirm the classification of the COL2-3/4C and COL2$1 / 4 \mathrm{~N} 2$ antibodies as antineoepitope antibodies recognizing only the termini of $\alpha 1$ chains of $\mathrm{TC}^{\mathrm{A}}$ and $\mathrm{TC}^{\mathrm{B}}$ produced by the action of mammalian collagenases on type II triple helical collagens.

None of the antibodies reacted to cleaved human type III collagen fragments produced by either MMP-1, MMP-8, or MMP-13, but all reacted to similarly cleaved fragments of human type I collagen (data not shown), confirming the results of the immunoassays that were mentioned above. Type X collagen is a minor cartilage collagen that has recently been demonstrated in OA articular cartilage (55) and it is susceptible to cleavage by the mammalian collagenases. None of the antibodies showed reactivity to intact or MMP-1 cleaved alpha chain fragments of this collagen (data not shown).

The collagenase-generated neoepitope (COL2-3/4C) is significantly elevated in $O A$ articular cartilage and is correlated to the amount of type II collagen denaturation

Human articular cartilage from the femoral condyles of $26 \mathrm{OA}$ (Mankin grade 3-12) and 19 nonarthritic (Mankin grade 1-5) joints were treated with $\alpha$-chymotrypsin to extract denatured type II collagen and to assay for COL2-3/4C neoepitope content. The median of the levels of COL2-3/4C epitope extracted from the OA specimens was significantly higher $(P=0.0002)$ than that of the nonarthritic articular cartilages (Fig. 8). Moreover, when the collagenase-generated neoepitope (expressed as a percentage of total collagen present) was compared to the percentage denatured collagen, based on COL2-3/4m intrachain epitope content in each extract, there were significant correlations found for both the nonarthritic $(r=0.503, P=$ 0.028; Fig. $9 A)$ and the OA $(r=0.536, P=0.0048$; Fig. $9 B)$ samples. The content of intrachain epitope was about twice that of the collagenase-generated neoepitope (by immunoas- 


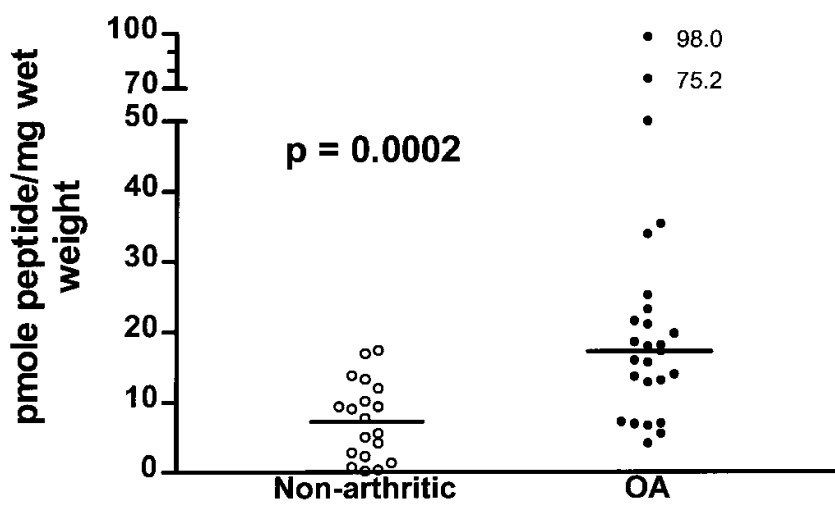

Figure 8. Levels of COL2-3/4C neoepitope in $\alpha$-chymotrypsin extracts of human articular cartilage. Articular cartilage was removed from the femoral condyles of 19 nonarthritic (patient ages: 20-69 yr; median, $60 \mathrm{yr}$ ) and 26 OA (patient ages: $44-85 \mathrm{yr}$; median $71 \mathrm{yr}$ ) joints and digested overnight at $37^{\circ} \mathrm{C}$ with $1 \mathrm{mg} / 50-75 \mathrm{mg}$ wet weight of $\alpha$-chymotrypsin in $50 \mathrm{mM}$ Tris- $\mathrm{HCl}, \mathrm{pH} 7.6(+$ the proteinase inhibitors: $1 \mathrm{mM}$ EDTA, $1 \mathrm{mM}$ iodoacetamide, and $10 \mu \mathrm{g} / \mathrm{ml}$ pepstatin A). After inhibition of enzyme activity with $160 \mu \mathrm{g} / \mathrm{ml} \mathrm{TPCK}$, the samples were centrifuged and the supernatants were assayed for COL2-3/4C neoepitope as discussed in Methods. The levels of the neoepitope are expressed as pmole of peptide (based on a molecular weight of $608 \mathrm{D}$ ) per $\mathrm{mg}$ wet weight of cartilage. The absolute values of the two highest neoepitope concentrations for the OA extracts are shown in the figure. A significant difference between the median of neoepitope content in the nonarthritic $(O)$ and the $\mathrm{OA}(\bullet)$ cartilages was determined by Mann-Whitney analysis and the $P$ value is shown in the figure.

say) suggesting an increased half-life of the former in both groups of cartilages.

No significant correlations (by Spearman rank analyses) were noted between Mankin grade and either percentage cleaved or percentage denatured collagen (data not shown). However, it is interesting to note that there was a tendency towards an increase in percentage collagenase cleaved collagen with increasing age $(P=0.054)$, that may reach significance with the sampling of more specimens.

Preferential inhibition of MMP-13 abrogates the release of the collagenase-generated COL2-3/4C neoepitope from human

$O A$ articular cartilage explants

Explant cultures of human condylar articular cartilages from three different patients were analyzed for the release of COL2-3/4C neoepitope into culture media. There was a steady release of COL2-3/4C into culture media over the $12 \mathrm{~d}$ of culture. An example of one of the three studies (OA sample 15) is shown (Fig. 10). In an attempt to determine if and which of the collagenases MMP-1, MMP-8, and MMP-13 may be responsible for the generation and/or release of the COL2-3/4C neoepitope, explants from the same specimens were also incubated with different concentrations (1-10 nM) of a preferential inhibitor of MMP-13, RS 102,481 (see Methods for inhibition profile). In all these studies, the inhibitor produced a significant reduction in the release of the COL2-3/4C neoepitope into the culture media over the $12 \mathrm{~d}$ of culture (Fig. 10).

That RS 102,481 did not have a detrimental effect on chondrocyte viability was determined by the measurement of total collagen synthesis. In two separate experiments there were no significant differences between the levels of tritiated hydroxyproline synthesized in OA cartilages cultured with or without
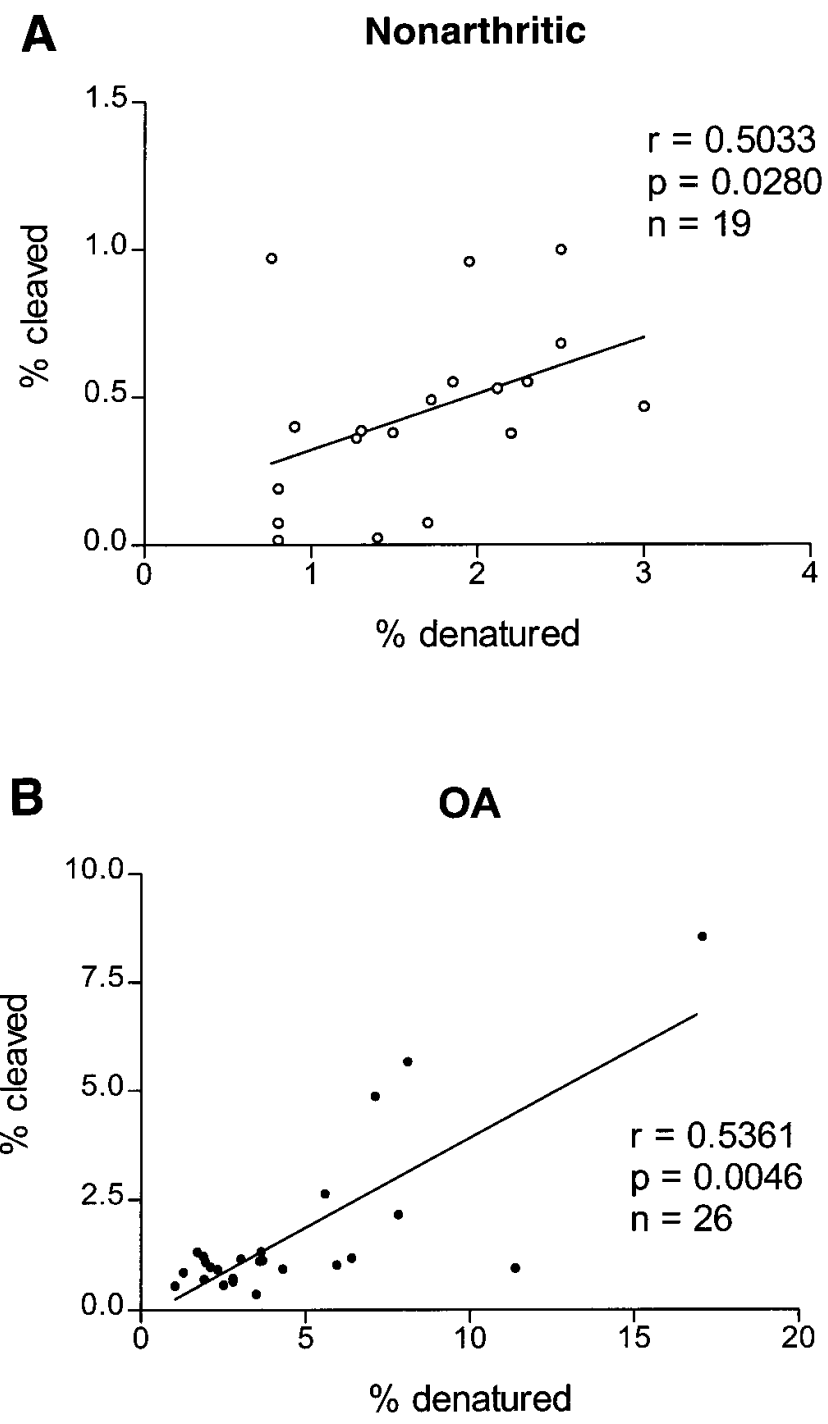

Figure 9. Correlation between the percent cleaved and the percent denatured type II collagen in $\alpha$-chymotrypsin extracts of human articular cartilage. The same articular cartilage specimens digested with $\alpha$-chymotrypsin and described in the legend of Fig. 8, were further digested overnight at $56^{\circ} \mathrm{C}$ with $1 \mathrm{mg}$ proteinase $\mathrm{K}$ in Tris- $\mathrm{HCl}, \mathrm{pH} 7.6$ (+ proteinase inhibitors) and then boiled for $20 \mathrm{~min}$ to inactivate the enzyme. The total type II collagen content was determined from the amount of COL2-3/4m epitope assayed in both the $\alpha$-chymotrypsin extracts and the proteinase $\mathrm{K}$ digests, as described in Methods. The percent denatured collagen represented the amount of COL2-3/4m and the percent cleaved collagen was the amount of COL2-3/4C in the $\alpha$-chymotrypsin extracts and both are expressed as a percentage of the total type II collagen. Statistically significant relationships between percent cleaved and percent denatured type II collagen in $(A)$ the nonarthritic $(O)$ and $(B)$ the $\mathrm{OA}(\bullet)$ articular cartilage specimens were determined by Spearman rank correlational analysis and the corresponding $n, r$ and $P$ values are shown in the figure.

the inhibitor at the highest concentration, namely $10 \mathrm{nM}$ (Table I).

\section{Discussion}

We have previously shown that OA, which involves the progressive degeneration of articular cartilages, is characterized 
OA 15

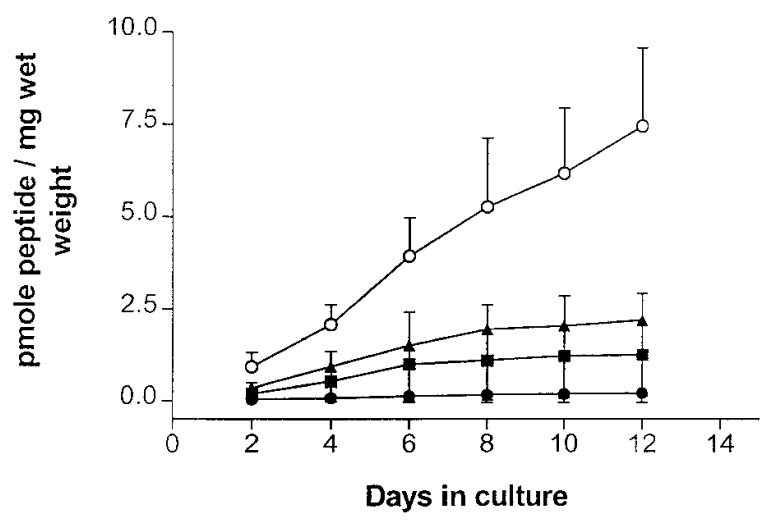

Figure 10. The effect of a synthetic preferential inhibitor of MMP-13 on the release of COL2-3/4C neoepitope from human osteoarthritic articular cartilage explants. The explants were cultured in basic culture medium (+DMSO) $(\bigcirc)$ or in the presence of RS 102,481, a preferential inhibitor of MMP-13, at $1.0(\boldsymbol{\Delta}), 2.5(\mathbf{\square})$, and $10(\bullet) \mathrm{nM}$. Media and inhibitor were replaced every $2 \mathrm{~d}$ and the conditioned media were assayed for COL2-3/4C neoepitope content. Shown is the cumulative release of the COL2-3/4C epitope over $12 \mathrm{~d}$ of a representative study (mean \pm SD), using OA sample 15 .

by increased denaturation of type II collagen $(6,7)$, a molecule essential for the maintenance of the tensile properties of this tissue, its molecular architecture, and its survival. The collagenases MMP-1, MMP-8, and MMP-13 are the only proteinases currently known to be capable of initiating the denaturation of fibrillar collagens, such as type II, by first cleaving the triple helix of this molecule. Primary cleavage occurs at a single site within the triple helix, producing approximately $3 / 4$ and $1 / 4$ length denatured $\alpha$ chain fragments $\mathrm{TC}^{\mathrm{A}}$ and $\mathrm{TC}^{\mathrm{B}}$, respectively. We have produced antibodies that recognize the aminoand carboxy-termini (neoepitopes) of this cleavage site in type II collagen. We used these antibodies to further characterize the cleavage of type II collagen by MMP-1, MMP-8, and MMP- 13 . These studies show that there is continued processing at the amino terminus of $\mathrm{TC}^{\mathrm{B}}$ by all these collagenases to produce first a secondary cleavage site at $\mathrm{Gly}_{778}-\mathrm{Gln}_{779}$, and then further cleavage(s) leading to the release or cleavage of these neoepitopes. An antibody was prepared against the secondary amino-terminal neoepitope of $\mathrm{TC}^{\mathrm{B}}$ and was used to demonstrate its production by MMP-1, MMP-8, and MMP-13. There

Table I. The Lack of an Effect of the Synthetic Collagenase Inhibitor RS 102,481 (10 nM) on Total Collagen Synthesis in Explant Cultures of Human OA Articular Cartilage

\begin{tabular}{lcc}
\hline & Control & RS 102,481 \\
\hline & $c p m / m g$ wet weight & $c p m / m g$ wet weight \\
Experiment 1 & $1968.3(534.6)$ & $1911.4(770.7)$ \\
Experiment 2 & $941.4(133.8)$ & $1131.9(38.7)$ \\
\hline
\end{tabular}

The amount of $\left[{ }^{3} \mathrm{H}\right]$ hydroxyproline synthesized from $\left[{ }^{3} \mathrm{H}\right]$ proline was determined in cartilage that had been labeled with [ $\left.{ }^{3} \mathrm{H}\right]$ proline on days $14-20$ of culture, as described in Methods. Values are expressed as mean (SD). was evidence for continued processing at the $\mathrm{COOH}$ terminus of $\mathrm{TC}^{\mathrm{A}}$ by MMP-13, albeit at a much slower rate compared to $\mathrm{TC}^{\mathrm{B}} \mathrm{NH}_{2}$-terminal processing. Moreover, the apparent greater resistance of the $\mathrm{COOH}$ terminus of $\mathrm{TC}^{\mathrm{A}}$ to secondary proteolysis, as compared to the $\mathrm{NH}_{2}$ terminus of $\mathrm{TC}^{\mathrm{B}}$, suggested to us that it would be more useful to assay for the COL2-3/4C neoepitope as an indicator of collagenase cleavage of type II collagen, as was done for the immunochemical analyses in this study.

Significant correlations were noted between percentage cleaved collagen (as determined by immunoassay for the COL2-3/4C neoepitope) and percentage denatured collagen (calculated from immunoassay for the COL2-3/4m intrachain epitope) in the immunoassays of extracts of human OA articular cartilage. These correlations were evident in both nonarthritic and OA specimens. These findings support the dogma that collagenase activity plays a key role in the denaturation and subsequent degradation of type II collagen in normal and OA articular cartilages. However, in view of the differences in epitope content being usually lower for the collagenase-generated epitope, it would seem that this epitope is preferentially lost from the cartilage. This loss of the epitope could be detected in culture. Because it was inhibited by a preferential MMP-13 inhibitor, there is thus evidence presented here to suggest that MMP-13 may play a significant role in the cleavage of type II collagen.

Recent studies of normal and OA cartilages have provided evidence for the expression of MMP-1 in normal and OA cartilages (26) and the increased expression and protein content of MMP-8 (29) and MMP-13 $(14,26)$ in OA cartilages. With the new technology described in this paper, we can now show that the increased expression of MMP-13 and MMP-8 is associated with increased cleavage by collagenase(s) of type II collagen in OA. Other collagenases responsible for this cleavage remain to be identified in human OA articular cartilage, but clearly all three are candidates. By demonstrating the production of the cleavage site that is only produced by collagenases, our study is the first to definitively implicate the activity of a collagenase in the cleavage of type II collagen in human articular cartilage and its increased activity in OA. Whether MMP-13 does in fact play a major role in this cleavage, as is suggested by the inhibitor studies, is presently being investigated by us. In view of the $K_{i}$ values, it is conceivable that the inhibitor may also block MMP-8 activity at the higher concentrations. However, it is unlikely that MMP-1 would be affected. In separate studies of cultured bovine articular cartilage explants stimulated with IL-1, we can show a similar significant reduction in the detection of the COL2-3/4C neoepitope in media when these cultures included the same collagenase inhibitor (Billinghurst, R.C., M. Ionescu, A. Reiner, W. Wu, J. Chen, H. Van Wart, and A.R. Poole, manuscript in preparation). Thus, combined with its capacity to preferentially cleave type II collagen as demonstrated here and by others $(10,14)$, MMP-13, and possibly MMP-8, are identified as potential targets for therapeutic intervention in $\mathrm{OA}$.

In parallel studies that will be published separately, we have shown that in cultured OA cartilage there is an increased release over normal tissue of the COL2-3/4C neoepitope. This combined with our ability to detect type II collagen degradation products in body fluids (Billinghurst, R.C., M. Ionescu, and A.R. Poole, manuscript in preparation) means that the increased degradation of type II collagen by collagenase in OA 
is a fundamental feature of this arthritis, and that its measurement in vivo may be of value in studying disease activity and its clinical management.

\section{Acknowledgments}

This manuscript is dedicated to Dr. J. Gross on the occasion of his 80th birthday. The authors wish to thank Elisa de Miguel for the preparation of the synthetic peptides, Ivan Otterness of Pfizer Central Research, Connecticut, for his generous assistance and support in establishing the collaborative studies on the recombinant collagenases, and Jane Wishart for her assistance with the figures.

Funding was provided by the Fonds de la Recherche en Sante du Quebec (to R.C. Billinghurst); the Swedish Society of Medicine, Wenner-Gren Center Foundation, and Swedish Center for Research in Sports (to L. Dahlberg); the Shriners of North America, the Medical Research Council of Canada, Searle Monsanto, St. Louis, MO, Pharmacia Diagnostics AB, Uppsala, Sweden, and the National Institutes of Health (to A.R. Poole).

\section{References}

1. Eyre, D.R. 1987. Collagen cross-linking amino acids. Methods Enzymol. 144:115-139.

2. Kempson, G.E., H. Muir, C. Pollard, and M. Tuke. 1973. The tensile properties of the cartilage of human femoral condyles related to the content of collagen and glycosaminoglycans. Biochim. Biophys. Acta. 297:465-472.

3. Poole, A.R. 1993. Cartilage in health and disease. In Arthritis and Allied Conditions: A Textbook of Rheumatology. D.J. McCarty and W.J. Koopman, editors. Lea and Febiger, Philadelphia. 279-333.

4. McAnulty, R.J., and G.J. Laurent. 1990. In vivo measurement of collagen metabolism in cartilage and bone. In Methods in Cartilage Research. A. Maroudas and K. Kuettner, editors. Academic Press Inc., San Diego, CA. 140-142.

5. Dodge, G.R., and A.R. Poole. 1989. Immunohistochemical detection and immunochemical analysis of type II collagen degradation in human normal, rheumatoid and osteoarthritic articular cartilages and in explants of bovine articular cartilage cultured with interleukin-1. J. Clin. Invest. 83:647-661.

6. Hollander, A.P., T.F. Heathfield, C. Webber, Y. Iwata, R. Bourne, C. Rorabeck, and A.R. Poole. 1994. Increased damage to type II collagen in osteoarthritic articular cartilage detected by a new immunoassay. J. Clin. Invest. 93:1722-1732.

7. Hollander, A.P., I. Pidoux, A. Reiner, C. Rorabeck, R. Bourne, and A.R. Poole. 1995. Damage to type II collagen in aging and osteoarthritis starts at the articular surface, originally around chondrocytes, and extends into the cartilage with progressive degeneration. J. Clin. Invest. 96:2859-2869.

8. Liu, X., H. Wu, M. Byrne, J. Jeffrey, S. Krane, and R. Jaenisch. 1995. A targeted mutation at the known collagenase cleavage site in mouse type I collagen impairs tissue remodelling. J. Cell Biol. 130:227-237.

9. Freije, J.M.P., I. Diez-Itza, M. Balbin, L.M. Sanchez, R. Blasco, J. Tolivia, and C. Lopez-Otin. 1994. Molecular cloning and expression of collagenase-3, a novel human matrix metalloproteinase produced by breast carcinomas. J. Biol. Chem. 269:16766-16773.

10. Knauper, V., C. Lopez-Otin, B. Smith, G. Knight, and G. Murphy. 1996. Biochemical characterization of human collagenase-3.J. Biol. Chem. 271:1544-1550.

11. Wu, J.J., M.W. Lark, L.E. Chun, and D.R. Eyre. 1991. Sites of stromelysin cleavage in collagen types II, IX, X, and XI of cartilage. J. Biol. Chem. 266: $5625-5628$

12. Miller, E.J., E.D. Harris, Jr., E. Chung, J.E. Finch, Jr., P.A. McCroskery, and W.T. Butler. 1976. Cleavage of type II and III collagen with mammalian collagenase: site of cleavage and primary structure at the $\mathrm{NH}_{2}$-terminal portion of the smaller fragment released from both collagens. Biochemistry. 15:787-792.

13. Hasty, K.A., T.F. Pourmotabbed, G.I. Goldberg, J.P. Thompson, D.G. Spinella, R.M. Stevens, and C.L. Mainardi. 1990. Human neutrophil collagenase: a distinct gene product with homology to other matrix metalloproteinases. J. Biol. Chem. 265:11421-11424.

14. Mitchell, P.G., H.A. Magna, L.M. Reeves, L.L. Lopresti-Morrow, S.A. Yocum, P.J. Rosner, K.F. Geoghegan, and J.E. Hambor. 1996. Cloning, expression, and type II collagenolytic activity of matrix metalloproteinase-13 from human osteoarthritic cartilage. J. Clin. Invest. 97:761-768.

15. Welgus, H.G., J.J. Jeffrey, G.P. Stricklin, and A.Z. Eisen. 1982. The gelatinolytic activity of human skin fibroblast collagenase. J. Biol. Chem. 257: 11534-11539.

16. Walakovits, L.A., V.L. Moore, N. Bhardwaj, G.S. Gallick, and M.W. Lark. 1992. Detection of stromelysin and collagenase in synovial fluid from patients with rheumatoid arthritis and posttraumatic knee injury. Arthritis Rheum. $35: 35-42$.
17. Clark, I.M., L.K. Powell, S. Ramsey, B.I. Hazleman, and T.E. Cawston. 1993. The measurement of collagenase, tissue inhibitor of metalloproteinases (TIMP), and collagenase-TIMP complex in synovial fluids from patients with osteoarthritis and rheumatoid arthritis. Arthritis Rheum. 36:372-379.

18. Lohmander, L.S., L.A. Hoerrner, and M.W. Lark. 1993. Metalloproteinases, tissue inhibitor, and proteoglycan fragments in knee synovial fluid in human osteoarthritis. Arthritis Rheum. 36:181-189.

19. Maeda, S., T. Sawai, M. Uzuki, Y. Takahashi, H. Omoto, M. Seki, and M. Sakvrai. 1995. Determination of interstitial collagenase (MMP-1) in patients with rheumatoid arthritis. Ann. Rheum. Dis. 54:970-975.

20. Gravallesse, E.M., J.M. Darling, A.L. Ladd, J.N. Katz, and L.H. Glimcher. 1991. In situ hybridization studies of stromelysin and collagenase messenger RNA expression in rheumatoid synovium. Arthritis Rheum. 34:1076-1084.

21. Firestein, G.S., M.M. Paine, and B.H. Littman. 1991. Gene expression (collagenase, tissue inhibitor of metalloproteinases, complement, and HLADR) in rheumatoid arthritis and osteoarthritis synovium. Arthritis Rheum. 34: 1094-1105.

22. Wolfe, G.C., K.L. MacNaul, F.F. Buechel, J. McDonnell, L.A. Hoerrner, M.W. Lark, V.L. Moore, and N.I. Hutchinson. 1993. Differential in vivo expression of collagenase messenger RNA in synovium and cartilage. Arthritis Rheum. 36:1540-1547.

23. Keyszer, G.M., A.H. Heer, J. Kriegsmann, T. Geiler, A. Trabandt, M. Keysser, R.E. Gay, and S. Gay. 1995. Comparative analysis of cathepsin L, cathepsin D, and collagenase messenger RNA expression in synovial tissues of patients with rheumatoid arthritis and osteoarthritis, by in situ hybridization. Arthritis Rheum. 38:976-984.

24. Wernicke, D., C. Seyfert, B. Hinzmann, and E. Gromnica-Ihle. 1996. Cloning of collagenase- 3 from the synovial membrane and its expression in rheumatoid arthritis and osteoarthritis. J. Rheumatol. 23:590-595.

25. Reboul, P., J.-P. Pelletier, G. Tardif, J.-M. Cloutier, and J. Martel-Pelletier. 1996. The new collagenase, collagenase-3, is expressed and synthesized by human chondrocytes but not by synoviocytes. J. Clin. Invest. 97:2011-2019.

26. Borden, P., D. Solymar, A. Swcharczuk, B. Lindman, P. Cannon, and R.A. Heller. 1996. Cytokine control of interstitial collagenase and collagenase-3 gene expression in human chondrocytes. J. Biol. Chem. 271:23577-23581.

27. Tetlow, L.C., and D.E. Woolley. 1995. Mast cells, cytokines, and metalloproteinases at the rheumatoid lesion: dual immunolocalisation studies. Ann. Rheum. Dis. 54:896-903.

28. Blair, H.C., D.D. Dean, D.S. Howell, S.L. Teitelbaum, and J.J. Jeffrey. 1989. Hypertrophic chondrocytes produce immunoreactive collagenase in vivo. Connect Tissue Res. 23:65-73.

29. Chubinskaya, S., K. Huch, K. Mikecz, G.Cs-Szabo, K.A. Hasty, K.E. Kuettner, and A.A. Cole. 1996. Chondrocyte matrix metalloproteinase-8: upregulation of neutrophil collagenase by interleukin- $1 \beta$ in human cartilage from knee and ankle joints. Lab. Invest. 74:232-240.

30. Cole, A.A., S. Chubinskaya, B. Schumacher, K. Huch, G. Cs-Szabo, J. Yao, K. Mikecz, K.A. Hasty, and K.E. Kuettner. 1996. Chondrocyte matrix metalloproteinase-8. Human articular chondrocytes express neutrophil collagenase. J. Biol. Chem. 271:11023-11026.

31. Cawston, T.E., and A.J. Barrett. 1979. A rapid and reproducible assay for collagenase using $\left[\mathrm{I}^{14} \mathrm{C}\right]$ acetylated collagen. Anal. Biochem. 99:340-345.

32. Dean, D.D., and J.F. Woessner, Jr. 1985. A sensitive, specific assay for tissue collagenase using telopeptide-free $\left[{ }^{3} \mathrm{H}\right]$ acetylated collagen. Anal. Biochem. 148:174-181.

33. Nagai, Y., C.M. Lapiere, and J. Gross. 1966. Tadpole collagenase. Preparation and purification. Biochemistry. 5:3123-3130.

34. Karran, E.H., K. Dodgson, S.J. Harris, R.E. Markwell, and G.P. Harper. 1995. A simple in vivo model of collagen degradation using collagen-gelled cotton buds: the effects of collagenase inhibitors and other agents. Inflamm. Res. 44:36-46.

35. Knight, C.G., F. Willenbrook, and G. Murphy. 1992. A novel coumarinlabeled peptide for sensitive continuous assays of the matrix metalloproteinases. FEBS (Fed. Eur. Biochem. Soc.) Lett. 296:263-266.

36. Clark, I.M., J.K. Wright, T.E. Cawston, and B.L. Hazleman. 1992. Polyclonal antibodies against human fibroblast collagenase and the design of an enzyme-linked immunosorbent assay to measure TIMP-collagenase complex. $\mathrm{Ma}$ trix. 12:108-115.

37. Clark, I.M., L.K. Powell, J.K. Wright, T.E. Cawston, and B.L. Hazleman. 1992. Monoclonal antibodies against human fibroblast collagenase and the design of an enzyme-linked immunosorbent assay to measure total collagenase. Matrix. 12:475-480.

38. Plumpton, T.A., I.M. Clark, C. Plumpton, J. Calvin, and T.E. Cawston. 1995. Development of an enzyme-linked immunosorbent assay to measure tota TIMP-1 (free TIMP-1 and TIMP-1 in combination with matrix-metalloproteinases) and measurement of TIMP-1 and CRP in serum. Clin. Chim. Acta. 240:137-154.

39. Hughes, C.E., B. Caterson, R.J. White, P.J. Roughley, and J.S. Mort. 1992. Monoclonal antibodies recognizing protease-generated neoepitopes from cartilage proteoglycan degradation. J. Biol. Chem. 267:16011-16014.

40. Mort, J.S., G.R. Dodge, P.J. Roughley, J. Liu, S.J. Finch, G. DiPasquale, and A.R. Poole. 1993. Direct evidence for active metalloproteinases mediating matrix degradation in interleukin 1-stimulated articular cartilage. Matrix. 13: 
95-102.

41. Bayne, E.K., K.L. MacNaul, S.A. Donatelli, A. Christen, P.R. Griffen, L.A. Hoerrner, J.R. Calaycay, J.M. Ayala, K. Chapman, W. Hagmann, et al. 1995. Use of an antibody against the matrix metalloproteinase-generated aggrecan neoepitope FVDIPEN-COOH to assess the effects of stromelysin in a rabbit model of cartilage degradation. Arthritis Rheum. 35:35-42.

42. Fosang, A.J., K. Last, P. Gardiner, D.C. Jackson, and L. Brown. 1995. Development of a cleavage-site-specific monoclonal antibody for detecting metalloproteinase-derived aggrecan fragments: detection of fragments in human synovial fluids. Biochem. J. 310:337-343.

43. Hughes, C.E., B. Caterson, A. Fosang, P.J. Roughley, and J.S. Mort. 1995. Monoclonal antibodies that specifically recognize neoepitope sequences generated by "aggrecanase" and matrix metalloproteinase cleavage of aggrecan: application to catabolism in situ and in vitro. Biochem. J. 305:799-804.

44. Lark, M.W., H. Williams, L.A. Hoerrner, J. Weidner, J.M. Ayala, C.F. Harper, A. Christen, J. Olszewski, Z. Konteatis, R. Webber, and R.A. Mumford. 1995. Quantification of a matrix metalloproteinase-generated aggrecan G1 fragment using monospecific anti-peptide serum. Biochem. J. 307:245-252.

45. Singer, I.I., D.W. Kawka, E.K. Bayne, S.A. Donatelli, J.R. Weidner, H.R. Williams, J.M. Ayala, R.A. Mumford, M.W. Lark, T.T. Glant, et al. 1995. VDIPEN, a metalloproteinase-generated neoepitope, is induced and immunolocalized in articular cartilage during inflammatory arthritis. J. Clin. Invest. 95:2178-2186.

46. Altman, R., E. Asch, D. Bloch, G. Bole, D. Borenstein, K. Brandt, W. Christy, T.D. Cooke, R. Greenwald, M. Hochberg, et al. 1986. Development of criteria for the classification and reporting of osteoarthritis. Classification of osteoarthritis of the knee. Arthritis Rheum. 29:1039-1049.
47. Miller, E.J. 1971. Isolation and characterization of a collagen from chick cartilage containing three identical $\alpha$ chains. Biochemistry. 10:1652-1659.

48. ChandraRajan, J. 1978. Separation of type III collagen from type I collagen and pepsin by differential denaturation and renaturation. Biochem. Biophys. Res. Commun. 83:180-186.

49. Tschesche, H. 1995. Human neutrophil collagenase. In Methods in Enzymology, Vol. 248. A.J. Barrett, editor. Academic Press Inc., San Diego, CA. 431-449.

50. Birkedal-Hansen, H., W.G.I. Moore, M.K. Bodden, L.J. Windsor, B. Birkedal-Hansen, A. DeCarlo, and J.A. Engler. 1993. Matrix metalloproteinases: a review. Crit. Rev. Oral Biol. Med. 4:197-250.

51. Poole, A.R., I. Pidoux, A. Reiner, L.-H. Tang, J. Choi, and L. Rosenberg. 1980. Localization of proteoglycan monomer and link protein in the matrix of bovine articular cartilage. J. Histochem. Cytochem. 28:621-635.

52. Laemmli, U.K. 1970. Cleavage of structural proteins during the assembly of the head of bacteriophage T4. Nature (Lond.). 227:680-685.

53. Mankin, H.J., H. Dorfman, L. Lippiello, and A. Zarins. 1971. Biochemical and metabolic abnormalities in articular cartilage from osteoarthritic human hips. II. Correlation of morphology with biochemical and metabolic data. $J$. Bone Jt. Surg. 53A:523-537.

54. Tyler, J. A., and H.P. Benton. 1988. Synthesis of type II collagen is decreased in cartilage cultured with interleukin 1 while the rate of intracellular degradation remains unchanged. Collagen Relat. Res. 8:393-405.

55. Girkontaite, I., S. Frischholz, P. Lammi, K. Wagner, B. Swoboda, T. Aigner, and K. von der Mark. 1996. Immunolocalization of type X collagen in normal fetal and adult osteoarthritic cartilage with monoclonal antibodies. $\mathrm{Ma}$ trix Biol. 15:231-238. 